NBER WORKING PAPER SERIES

\title{
DOES "BAN THE BOX" HELP OR HURT LOW-SKILLED WORKERS? STATISTICAL DISCRIMINATION AND EMPLOYMENT OUTCOMES WHEN CRIMINAL HISTORIES ARE HIDDEN
}

\author{
Jennifer L. Doleac \\ Benjamin Hansen \\ Working Paper 22469 \\ http://www.nber.org/papers/w22469 \\ NATIONAL BUREAU OF ECONOMIC RESEARCH \\ 1050 Massachusetts Avenue \\ Cambridge, MA 02138 \\ July 2016
}

Thanks to Amanda Agan, Shawn Bushway, David Eil, Kirabo Jackson, Jonathan Meer, Sonja Starr, and participants at the 2016 IRP Summer Research Workshop for helpful comments and conversations. Thanks also to Emily Fox and Anne Jordan for excellent research assistance. This study was generously supported by the Russell Sage Foundation. The views expressed herein are those of the authors and do not necessarily reflect the views of the National Bureau of Economic Research.

NBER working papers are circulated for discussion and comment purposes. They have not been peer-reviewed or been subject to the review by the NBER Board of Directors that accompanies official NBER publications.

(C) 2016 by Jennifer L. Doleac and Benjamin Hansen. All rights reserved. Short sections of text, not to exceed two paragraphs, may be quoted without explicit permission provided that full credit, including $\odot$ notice, is given to the source. 
Does "Ban the Box" Help or Hurt Low-Skilled Workers? Statistical Discrimination and Employment Outcomes When Criminal Histories are Hidden

Jennifer L. Doleac and Benjamin Hansen

NBER Working Paper No. 22469

July 2016

JEL No. J15,J7,J78,K42

\begin{abstract}
$\underline{\text { ABSTRACT }}$
Jurisdictions across the United States have adopted "ban the box" (BTB) policies preventing employers from conducting criminal background checks until late in the job application process. Their goal is to improve employment outcomes for those with criminal records, with a secondary goal of reducing racial disparities in employment. However, removing information about job applicants' criminal histories could lead employers who don't want to hire ex-offenders to try to guess who the ex-offenders are, and avoid interviewing them. In particular, employers might avoid interviewing young, low-skilled, black and Hispanic men when criminal records are not observable. This would worsen employment outcomes for these already-disadvantaged groups. In this paper, we use variation in the details and timing of state and local BTB policies to test BTB's effects on employment for various demographic groups. We find that BTB policies decrease the probability of being employed by 3.4 percentage points $(5.1 \%)$ for young, low-skilled black men, and by 2.3 percentage points $(2.9 \%)$ for young, low-skilled Hispanic men. These findings support the hypothesis that when an applicant's criminal history is unavailable, employers statistically discriminate against demographic groups that are likely to have a criminal record.
\end{abstract}

Jennifer L. Doleac

Frank Batten School of Leadership \& Public Policy

University of Virginia

Charlottesville, VA 22904

jdoleac@virginia.edu

Benjamin Hansen

Department of Economics

1285 University of Oregon

Eugene, OR 97403

and NBER

bchansen@uoregon.edu 


\section{Introduction}

Mass incarceration was an important crime reduction policy during the past several decades, but it has come under intense scrutiny due to its high financial cost, diminishing public-safety returns, and collateral damage to the families and communities of those who are incarcerated. There is substantial interest in reallocating public resources to more cost-effective strategies, with greater emphasis on rehabilitating offenders. Due in part to this change in focus, individuals are now being released from state and federal prisons more quickly than they are being admitted. According to the most recent data, over 637,000 people are released each year (Carson and Golinelli, 2014). However, recent data also suggest that approximately two-thirds of those released will be re-arrested within three years (Cooper et al., 2014). This cycle signals our failure to help re-entering offenders transition to civilian life, and limits our ability to reduce incarceration rates. Breaking this cycle is a top policy priority.

Connecting ex-offenders with jobs is often considered a necessary - though not sufficient - step toward successful re-entry outcomes. The classic Becker (1968) model of criminal behavior suggests that better employment options for would-be offenders reduce crime. Individuals who have been convicted of a crime often have difficulty finding employment, which does appear to increase their likelihood of committing another crime (Schnepel, 2015, Yang, 2016). Part of the reason that finding employment is difficult for this group is that ex-offenders, on average, have less education and job experience than non-offenders. However, there is evidence that employers discriminate against those with criminal records, even when other observable characteristics are identical (Pager, 2003). This is likely due to statistical discrimination 1 On average, ex-offenders are more likely than non-offenders to have engaged in violent, dishonest, or otherwise antisocial behavior, and - based on current recidivism rates - are more likely to engage in similar behavior in the future $2^{2}$ Ex-offenders also have higher rates of untreated mental illness, addiction, and emotional trauma (Justice Center, 2016; Wolff and Shi, 2012). These are all valid concerns for employers seeking reliable, productive

\footnotetext{
${ }^{1}$ Some employers' discrimination could be taste-based - that is, they simply don't like ex-offenders, and no additional information about individuals with records could change their feelings. This distinction does not alter the predicted effects of "ban the box", but does matter when considering alternative policies.

${ }^{2}$ This not only affects an individual's expected tenure on the job, but increases potential financial costs to the employer. For instance, employers might worry about theft, or that future violent behavior could result in a negligenthiring lawsuit.
} 
employees. However, this reasoning is little comfort to someone coming out of prison and hoping to find gainful legal employment, but willing to revert to illegal activity if none can be found. In addition, since black and Hispanic men are more likely to have criminal records, making a clean record a condition for employment could exacerbate racial disparities in employment ${ }^{3}$

If even a few ex-offenders are more job-ready than some non-offenders, then employers' statistical discrimination against those with criminal records hurts the most job-ready ex-offenders. This has motivated the "ban the box" (BTB) movement, which calls for employers to delay asking about an applicant's criminal record until late in the hiring process. Advocates of BTB believe that if employers can't tell who has a criminal record, job-ready ex-offenders will have a better chance at getting an interview. During that interview, they will be able to signal their otherwise-unobservable job-readiness to the employer. This could increase employment rates for ex-offenders, and thereby decrease racial disparities in employment outcomes.

However, this policy does nothing to address the average job-readiness of ex-offenders. A criminal record is still correlated with lack of job-readines: 4 . For this reason, employers will still seek to avoid hiring individuals with criminal records. When BTB removes information about a criminal record from job applications, employers will likely respond by using the remaining observable information to try to guess who the ex-offenders are, and avoid interviewing them. Surveys by Holzer et al. (2006) show that employers are most concerned about hiring those who were recently incarcerated. Since young, low-skilled, black and Hispanic men are the most likely to fall in this category (Bonczar, 2003, Yang, 2016), employers may respond to BTB by avoiding interviews with these groups. As a result, racial disparities could increase rather than decrease.

This papers asks whether BTB is a net positive or negative for racial minorities. To answer this question, we exploit variation in the adoption and timing of state and local BTB policies to test BTB's effects on employment outcomes for various demographic groups, using individual-level data from the 2004-2014 Current Population Survey (CPS). We focus on the probability of employment for black and Hispanic men who are relatively young (age 25-34) $\bigsqcup^{5}$ and low-skilled (no college degree),

\footnotetext{
${ }^{3}$ The best data available suggest that a black man born in 2001 has a $32 \%$ chance of serving time in prison at some point during his lifetime, compared with $17 \%$ for Hispanic men and $6 \%$ for white men (Bonczar. 2003).

${ }^{4}$ We use "job-readiness" to refer to a range of characteristics that make someone an appealing employee, including reliability and productivity.

${ }^{5}$ We follow the literature and focus on individuals age 25 and over because most individuals have completed their
} 
as they are the ones most likely to be recently-incarcerated. This group contains the most intended beneficiaries of BTB as well as the most people who could be unintentionally hurt by the policy. If BTB enables some re-entering offenders to get their foot in the door and communicate their job-readiness to employers, we might see a positive effect on employment for this group. However, if young, low-skilled black and Hispanic men as a whole are now less likely to be called in for interviews, then the net effect on employment could be negative.

Indeed, we find net negative effects on employment for these groups: On average, young, lowskilled black men are 3.4 percentage points (5.1\%) less likely to be employed after BTB than before. This effect is statistically significant $(p<0.05)$ and robust to a variety of alternative specifications and sample definitions. We also find that BTB reduces employment by 2.3 percentage points $(2.9 \%)$ for young, low-skilled Hispanic men. This effect is only marginally significant $(p<0.10)$ but also fairly robust. Both effects are unexplained by pre-existing trends in employment, and - for black men - persist long after the policy change. The effects are larger for the least skilled in this group (those with no high school diploma or GED), for whom a recent incarceration is more likely.

We expect BTB's effects on employment to vary with the local labor market context. For instance, it would be difficult for an employer to discriminate against all young, low-skilled black men if the local low-skilled labor market consists primarily of black men, or if there are very few applicants for any open position. We find evidence that such differential effects exist. BTB reduces black male employment significantly everywhere but in the South (where a larger share of the population is black). Similarly, BTB reduces Hispanic male employment everywhere but in the West (where a larger share of the population is Hispanic). This suggests that employers are less likely to use race as a proxy for criminality in areas where the minority population of interest is larger - perhaps because discriminating against that entire set of job applicants is simply infeasible. In addition, we find evidence that statistical discrimination based on race is less prevalent in tighter labor markets: BTB's negative effects on black and Hispanic men are larger when national unemployment is higher. In other words, employers are more able to exclude broad categories of job applicants in order to avoid ex-offenders when applicants far outnumber available positions.

education by that age. In our sample, only about $1 \%$ of low-skilled men ages 25-34 are enrolled in school. Since we are using education level as a proxy for skill level, using final education increases the precision of our estimates (relative to, for instance, considering all 19 year olds "low-skilled" because they don't yet have a college degree). 
Our hypothesis is that employers are less likely to interview young, low-skilled black and Hispanic men because these groups include a lot of ex-offenders. This hypothesis suggests that employers will instead interview and hire individuals from demographic groups unlikely to include recent offenders. We find some evidence suggesting that this does indeed happen. Older, low-skilled black men and highly-educated black women are significantly more likely to be employed after BTB 6 Effects on white men and women are also positive, though statistically insignificant. However, total employment might go down when employers are not able to see which applicants have criminal records. BTB increases the expected cost of interviewing job applicants, because there's a higher chance that any interview could end in a failed criminal background check. In addition, while employers might be willing to substitute college graduates or others who are clearly job-ready, those individuals might not be willing to accept a low-skilled job at the wage the employer is willing to pay $!^{7}$ Indeed, we find no effect on employment for men with college degrees.

We are not the only researchers interested in the effects of BTB on employment. Three other current papers study the effect of this policy: all find effects consistent with statistical discrimination. However, ours is the only one to focus on employment outcomes for young, low-skilled men - the group with the most to gain or lose from BTB, 8

Agan and Starr (2016) exploited the recent adoption of BTB in New Jersey and New York to conduct a field experiment on the effect of the policy on the likelihood of getting an interview. They submitted thousands of fake job applications from young, low-skilled men, randomizing the race and criminal history of the applicant. They found that before BTB white applicants were called back slightly more often than black applicants were. That gap became six times larger after BTB went into effect. White ex-offenders benefited the most from the policy change: after BTB, employers seem to assume that all white applicants are non-offenders. After BTB, black applicants were called back at a rate between the ex-offender and non-offender callback rates from before BTB - that is, those with records were helped, but those without records were hurt. Since the researchers

\footnotetext{
${ }^{6}$ The effect on black women could represent intrahousehold substitution, rather than substitution by employers. That is, women might be more likely to work when their partners are unable to find jobs.

${ }^{7}$ This is similar to the well-known "lemons problem" in economics, where asymmetric information between a buyer and seller causes a market to unravel and no transactions to be made (Akerlof, 1970).

${ }^{8}$ This distinction can potentially matter in quantifying the effects of policies in labor markets. For instance, Borjas (2015) finds that Mariel boatlift substantially reduced wages for low-skill prime working age males while Card (1990) found limited evidence of the labor supply shock affected the overall population.
} 
create the applications themselves, they kept other factors like education constant. The differences in interview rates before and after the policy change are therefore solely due to the changing factors - race and criminal history. The limitation of this approach is that fake applicants can't do real interviews that lead to real jobs. It's possible that the few ex-offenders granted interviews would be more likely to get the job after BTB implementation than before. However, if employers are reluctant to hire ex-offenders, those applicants might be rejected once their criminal history is revealed late in the process (between the interview and the job offer). These later steps are critical in determining the true social welfare consequences of BTB. Overall, our results are consistent with these changes in callback rates: young, low-skilled black men without records were hurt by BTB, and young, low-skilled white men might have been helped.

Starr (2015), available in early draft form, uses CPS data from 2004 to 2014 to measure the effect of BTB on government employment rates for black men ages 18 to 64. Preliminary results suggest that BTB reduced public employment for this group. There are several differences from our study: Starr limited her sample to specific cities that adopt BTB at some point, so non-BTB cities are not used as controls, and the analysis does not consider county or state BTB policies. She also does not consider effects of BTB policies on the full metro area, though that entire labor market is potentially treated. She focuses only on employment in government jobs, which are directly affected by public BTB policies. Finally, she does not consider effects on other demographic subgroups. Despite these different methods and samples, her findings are similar to ours.

Shoag and Veuger (2016) use annual 2005-2014 data from the American Community Survey (ACS) along with a difference-in-difference strategy, to consider the effects of BTB on residents of high-crime neighborhoods (a proxy for those with criminal records), using those living in low-crime neighborhoods (a proxy for those without criminal records) as a control group. They find that lowskilled black men ages 19-65 who live in high-crime neighborhoods do better after BTB, relative to those in low-crime neighborhoods, and interpret this as evidence that BTB has a beneficial effect on ex-offenders. However, using low-crime neighborhood residents as controls is problematic because they are also treated by the policy: if employers use race as a proxy for criminality in the absence of information about criminal histories, BTB will make those without criminal records worse off. BTB should shrink the employment gap between those with and without records, because they now look 
identical to employers. This is what the study finds. These effects are consistent with the theory described above and with our results.

Ban the box policies seek to limit employers' access to criminal histories. This access itself is relatively new. Before the internet and inexpensive computer storage became available in the 1990s, it was not easy to check job applicants' criminal histories. This is the world that BTB advocates would like to recreate. Of course this world differs from our own in many other respects, but nevertheless it is helpful to consider how employment outcomes changed as criminal records became more widely available during the 1990s and early 2000s. A number of studies address this, and their findings foreshadow our own: when information on criminal records is available, firms are more likely to hire low-skilled black men (Bushway, 2004, Holzer et al., 2006, Finlay, 2009, Stoll, 2009). In fact, many of those studies explicitly predicted that limiting information on criminal records, via BTB or similar policies, would negatively affect low-skilled black men as a group 9

There is plenty of evidence that statistical discrimination increases when information about employees is less precise. Autor and Scarborough (2008) measure the effects of personality testing by employers on hiring outcomes. Conditioning hiring on good performance on personality tests (such as popular Myers-Briggs tests) was generally viewed as disadvantaging minority job candidates because minorities tend to score lower on these tests. However, the authors note that this will only happen if employers' assumptions about applicants in the absence of information about test scores are more positive than the information that test scores provide. If, in contrast, minorities score better on these tests than employers would have thought, adding accurate information about a job

\footnotetext{
${ }^{9} \mathrm{~A}$ few striking quotes from that literature:
}

[S]ome advocates seek to suppress the information to which employers have access regarding criminal records. But it is possible that the provision of more information to these firms will increase their general willingness to hire young black men, as we show here and since we have previously found evidence that employers who do not have such information often engage in statistical discrimination against this demographic group. (Holzer et al. 2004)

Employers have imperfect information about the criminal records of applicants, so rational employers may use observable correlates of criminality as proxies for criminality and statistically discriminate against groups with high rates of criminal activity or incarceration. (Finlay, 2009)

[Ban the box] may in fact have limited positive impacts on the employment of ex-offenders.... More worrisome is the likelihood that these bans will have large negative impacts on the employment of those whom we should also be concerned about in the labor market, namely minority - especially black - men without criminal records, whose employment prospects are already poor for a variety of other reasons. (Stoll, 2009) 
applicant's abilities will help minority applicants. They find that in a national firm that was rolling out personality testing, the use of these tests had no effect on the racial composition of employees, though they did allow the firm to choose employees who were more productive.

Wozniak (2015) found that when employers required drug tests for employees, black employment rates increased by $7-30 \%$, with the largest effects on low-skilled black men. As in the personality test context, the popular assumption was that if black men are more likely to use drugs, employers' use of drug tests when making hiring decisions would disproportionately hurt this group. It turned out that a drug test requirement allowed non-using black men to prove their status when employers would otherwise have used race as a proxy for drug use.

In another related paper, Bartik and Nelson (2016) hypothesize that banning employers from checking job applicants' credit histories will negatively affect employment outcomes for groups that have lower credit scores on average (particularly black individuals). The reasoning is as above: in the absence of information about credit histories, employers will use race as a proxy for credit scores. They find that, consistent with statistical discrimination, credit check bans reduce job-finding rates by $7-16 \%$ for black job-seekers. As with BTB policies, one goal of banning credit checks was to reduce racial disparities in employment, so this policy was counterproductive.

Our study therefore contributes to a growing literature showing that well-intentioned policies that remove information about negative characteristics can do more harm than good 10 Advocates for these policies seem to think that in the absence of information, employers will assume the best about all job applicants. This is often not the case. In all of the above examples, providing information about characteristics that are less favorable, on average, among black job-seekers criminal records, personality tests, drug tests, and credit histories - actually helped black men and black women find jobs. These outcomes are what we would expect from standard statistical discrimination models. More information helps the best job candidates avoid discrimination.

The availability of criminal records is just one facet of an ongoing debate about data availability. Improvements in data storage and internet access have made a vast array of information about our

\footnotetext{
${ }^{10}$ An additional study focuses on a different population but its findings are consistent with the same statistical discrimination theory as those described above: Thomas $(2016)$ finds that when the Family and Medical Leave Act limited employers' information about female employees' future work plans, it decreased employers' investment in female employees as a group. After the FMLA, women were promoted at lower rates than before the law.
} 
pasts readily available to those in our present, including to potential employers, love interests, advertisers, and fraudsters. This often seems unfair to those who - like many ex-offenders - are trying to put their pasts behind them. The policy debate about whether and how to limit this data availability is complicated both by free speech concerns and logistical issues - once information is distributed publicly, what are the chances of being able to make it private again? Even so, a great deal of effort has gone into defining who should have access to particular data, often with the goal of improving the economic outcomes of disadvantaged groups 11 As this and related studies have shown, well-intentioned policies of this sort often have unintended consequences, and providing more information is often a better strategy.

This paper proceeds as follows: Section 2 provides background on BTB policies. Section 3 describes our data. Section 4 presents our empirical strategy. Section 5 describes our results. Section 6 presents robustness checks. Section 7 discusses and concludes.

\section{Background on BTB policies}

The first BTB law was implemented in Hawaii in 1998, and - as of December 2015 - similar policies exist in 34 states and the District of Columbia. In addition, President Obama "banned the box" on employment applications for federal government jobs in late 2015. Without BTB, it is common for employment applications to include a box that the applicant must check if he or she has been convicted of a crime, along with a question about the nature and date(s) of any convictions. Anecdotally, many employers simply discard the application of anyone who checks this box. BTB policies prevent employers from asking about criminal records until late in the hiring process, when they are preparing to make a job offer.

BTB policies fall into three broad categories: (1) those that affect public employers (that is, government jobs only), (2) those that affect private employers with government contracts, and (3) those that affect all private employers. We'll refer to these as "public BTB", "contract BTB", and "private BTB" policies, respectively. In practice, public BTB policies are the most common, and are

\footnotetext{
${ }^{11}$ See for example, the "right to be forgotten" movement in Europe, which included a ruling that - at a person's request - search engines must "remove results for queries that include the person's name" (Google, 2016). See also the White House's recent recommendations on consumer data privacy, available at https://www.whitehouse.gov/ sites/default/files/privacy-final.pdf
} 
passed first. Contract BTB policies are typically the next step. Private BTB policies are typically the final step a jurisdiction takes. Every jurisdiction in our sample with a contract BTB policy also has a public BTB policy. Similarly, every jurisdiction in our sample with a private BTB policy also has a contract BTB policy. Due to the relatively limited adoption of contract and private BTB policies to date, our analysis focuses primarily on the effects of having at least a public BTB policy.

There's reason to expect public BTB laws to affect both public and private sector jobs. Most importantly, these policies were typically implemented due to public campaigns aimed at convincing employers to give ex-offenders a second chance. Public BTB policies were intended in part to model the best practice in hiring, and there is anecdotal evidence that this model - in combination with public pressure - pushed private firms to adopt BTB even before they were legally required to. Indeed, several national private firms such as Wal-Mart, Target, and Koch Industries, voluntarily "banned the box" on their employment applications during this period, in response to the BTB social movement 12

Public BTB laws might also affect private sector jobs because workers are mobile between the two sectors, and likely sort themselves based on where they feel most welcome. Because BTB likely affected jobs in both sectors, we will focus on the net effect of BTB policies on the probability that individuals work at all.

\section{Data}

Our analysis considers BTB policies effective by December 2014. Figure1 1 maps the cities, counties, and states with BTB policies by that date ${ }^{13}$ Information on the timing and details of BTB policies comes primarily from NELP (2016). The details of local policies used in this analysis are listed in Table 3. When information about a policy's effective date was available, we used that date as the start date of the policy; otherwise we used the date the policy was announced or passed by the legislature. If only the year (month) of implementation was available, we used January 1 of that year (the first of that month) as the start date.

\footnotetext{
${ }^{12}$ We do not consider the effects of those voluntary bans here, but do note that a principal-agent problem could lead to the same effects as for government bans. A CEO might be inclined to hire ex-offenders, but the managers who are actually making the hiring decisions might still want to avoid supervising individuals with criminal records.

${ }^{13}$ Appendix Figure A-1 shows maps of BTB policies by year, for 2004 through 2014.
} 
Information on individual characteristics and employment outcomes comes from monthly Current Population Survey (CPS) data for 2004 through 2014 ${ }^{14}$ The CPS is a repeated cross-section that targets those eligible to work. It excludes anyone under age 15 as well as those in the Armed Forces or in an institution such as a prison. Each monthly sample consists of about 60,000 occupied households; the response rate averages 90 percent (CPS, 2016). Excluding those who are incarcerated could affect our analysis: If BTB increases recidivism and incarceration by making it more difficult to find a job, some of the people now unemployed because of the policy will be excluded from the CPS sample. Any such sample selection will bias our estimates upward, so that BTB policies look more helpful than they are.

The CPS provides information on age, sex, race, ethnicity, education level, and current employment (if employed, and employer type). Since our hypotheses center on statistical discrimination by race and ethnicity, we limit our analysis to individuals who are white non-Hispanic, black nonHispanic, or Hispanic (hereafter referred to as white, black, and Hispanic, respectively). We consider three levels of educational achievement: no high school diploma, no college degree, and college degree 15 We code someone as "employed" if they answer yes to the question, "Last week, did you do any work for pay?" This should be the most reliable measure of employment for our population of interest, for whom temporary, seasonal, or informal jobs are common. We restrict our sample to those who are U.S. citizens, and who do not consider themselves retired 16

Our goal is to measure the effect of BTB on individuals in the local labor market, so we assign treatment at the level of Metropolitan Statistical Areas (MSAs). All individuals are matched to states, and about three-quarters are matched to MSAs 17 We consider individuals treated by BTB

\footnotetext{
${ }^{14}$ We use the public-use CPS files available from the National Bureau of Economic Research (NBER). These raw data contain item non-response codes when a respondent did not answer a question, rather than imputed responses. Many studies use CPS data from the Integrated Public Use Microdata Series (IPUMS); in those files, all responses are fully cleaned and imputations replace non-responses. In light of increasing evidence of widespread non-response in surveys like the CPS, and the effect that imputations have on the accuracy and precision of empirical estimates (Meyer et al. 2015), we prefer the raw data, particularly for the relatively disadvantaged population of interest here.

${ }^{15}$ In the CPS, these are determined using the "highest level of school completed or degree received" variable. For our purposes, no high school diploma means the respondent has up to 12 years of high school but no diploma or GED; no college degree means the respondent has up through some college but did not earn an associate degree or bachelor degree; college means the person has an associate degree or higher. Note that the no high school diploma category is a subset of the "no college degree" category; these are two ways to define low-skilled and we focus on the latter to maximize statistical power.

${ }^{16}$ The data also include whether the respondent reports being disabled and/or unable to work, but we use these variables with caution as they could be endogenous to local labor market conditions and individuals' employment prospects.

${ }^{17}$ About half of respondents are matched to counties. Running our analysis at the county-level yields qualitatively
} 
if their state has a BTB policy, or if any jurisdiction in their MSA has a BTB policy. For individuals living outside of an MSA, only state-level policies matter.

Our primary group of interest is young (ages 25-34), low-skilled (no college degree) men. We focus on this group for several reasons: (1) The age profile of criminal offenders is such that most crimes are committed by young men. In 2012, $60 \%$ of criminal offenders were age 30 or younger (Kearney et al. 2014). So, employers concerned about job applicants' future criminal behavior should be most concerned about younger individuals. (2) Employers report the most reluctance to hire individuals who were recently incarcerated (Holzer et al., 2004), and those who are recently released tend to be young because they were young when they were convicted 18 (3) The vast majority of ex-offenders have a high school diploma (or GED) or less 19

There are 855,772 men ages $25-34$ in our sample; 503,419 of those have no college degree. In that subset, $11.9 \%$ are black, $14.0 \%$ are Hispanic, and the remaining $74.1 \%$ are white. Forty-six percent of the young, low-skilled men in our sample lived in areas that were treated by BTB as of December 2014.

Summary statistics for the full working-age male population (ages 25-64) in the CPS are shown in Table 1. Summary statistics for our primary population of interest - low-skilled men ages 25-34 - are presented in Table 2 .

Individuals affected by BTB policies are not randomly distributed across the U.S. As Table 2 shows, those affected by BTB are much more likely to live in metro areas. Appendix Table A-1 shows the effect of state characteristics on the likelihood of at least one jurisdiction in that state adopting a BTB policy by December 2014. States with BTB policies are more urban, have more black residents, have more college-educated residents, and have residents with higher earnings. When all of these characteristics are considered together, the strongest predictor of having a BTB policy is having a larger black population. (The remaining characteristics are statistically insignificant.)

For the subset of states affected by a BTB policy Appendix Table A-2 shows the effect of state similar but less precise results.

${ }^{18}$ Individuals released from state prison between 2000 and 2013 were 35 years old, on average, and the standard deviation was 11 years (Yang, 2016).

${ }^{19}$ Fifty-two percent of those released from state prison between 2000 and 2013 had less than a high school degree, and 41 percent had a high school degree but no college degree. Only 1\% of released offenders had a college degree (Yang, 2016). This is partly because many inmates have the opportunity to earn a GED while incarcerated, but college classes are typically unavailable.

${ }^{20}$ This includes states with residents affected by BTB policies adopted in neighboring states, because they live in 
characteristics on the date of the first BTB policy adopted in the state. States that are more urban tend to adopt BTB policies earlier, as do states with higher-earning residents. States with larger black populations tend to adopt BTB policies later, as do states with higher rates of poverty. When these characteristics are combined into a single regression, none of them are statistically significant, and the correlation between local poverty rates and BTB date reverses. However, the coefficients are still somewhat large.

Overall, this is a policy that has, so far, been adopted by urban areas. Those with larger black populations - and so presumably where black male employment is a more salient policy issue - are more likely to adopt BTB policies, although it appears that they were not the earliest adopters. The effects of BTB found in this paper should be considered in light of these associations: the results of this study speak to the effects of BTB in the types of jurisdictions that adopted the policy by December 2014. Given that areas that don't adopt BTB look different from those that do adopt BTB, we conduct robustness checks that use only similar jurisdictions as control groups. We also pay close attention to the "parallel trends" assumption of our difference-in-difference identification strategy.

\section{Empirical Strategy}

We consider the effect of BTB policies on the probability that individuals are employed, based on a linear probability model. We use the following specification:

$$
\text { Employed }_{i}=\alpha+\beta_{1} B T B_{m, t}+\beta_{2} \delta_{M S A}+\beta_{3} D_{i}+\beta_{4} \lambda_{\text {time*region }}+\beta_{5} \delta_{M S A} * f(\text { time })_{t}+e_{i},
$$

where $i$ indexes individuals. $\delta_{M S A}$ are MSA fixed effects. $D_{i}$ is a vector of individual characteristics that help explain variation in employment, including race, ethnicity, age fixed effects, fixed effects for years of education, and an indicator for whether the individual is currently enrolled in school. $\lambda_{\text {time*region }}$ are time-by-region fixed effects (where time is the month of the sample, 0 to 132 , and region is the Census region) ${ }^{21} \delta_{M S A} * f(\text { time })_{t}$ are MSA-specific time trends, using a linear MSAs that span state borders.

${ }^{21}$ Using Census division instead of region yields nearly identical results but is far more computationally intensive. 
function of time. BTB is equal to 1 if any BTB policy (affecting government employers and possibly government contractors and/or private firms) is in effect in the individual's MSA. Standard errors are clustered by state. The coefficient of interest, $\beta_{1}$, tells us the effect that a BTB policy has on the probability that an individual is employed.

To test for differential policy effects by race, we add $B T B *$ Black and BTB*Hispanic terms to equation 1 . Since low-skilled white men are not a control group - they could be helped or hurt by the policy - the differential effect is not the primary outcome of interest. We also compute the total effect of BTB on black men and Hispanic men $(B T B+B T B *$ Black and BTB $+B T B * H i s p a n i c$, respectively) to estimate the impact on each of these subgroups.

Our preferred specification fully interacts all of the control variables with race. This is equivalent to running the regressions separately by race, but still allows us to directly test for differential policy effects. Allowing this additional flexibility (where the effect of all controls can vary with race) reduces our statistical power and often has little effect on the estimates. However, for some subgroups it makes a difference. We view this fully-interacted specification as the most conservative approach. For the sake of transparency we will show how the main results change as each set of controls is added.

For each 25- to 34-year-old man in our sample, the full set of controls adjusts for: the average employment probability for men of the same race/ethnicity within his MSA, the employment trend for that race/ethnicity group in his MSA, monthly region-specific employment shocks (such as the housing crash), and his individual characteristics. Any remaining variation in his likelihood of employment would come from idiosyncratic, individual-level factors (for instance, an illness or a fight with a supervisor), or MSA-specific shocks that don't affect nearby MSAs - such as adoption of a BTB policy. Our identifying assumption is that the adoption and timing of BTB policies are exogenous to other interventions or local job market changes that might affect employment, so that - in the absence of BTB - employment probabilities would evolve similarly to those in nearby MSAs without the policy. The most likely threat to identification is that BTB policies were voluntarily adopted by areas that were motivated to help ex-offenders find jobs. The timing of these policies likely coincides with new, local interest in hiring those with criminal records. This should bias our estimated effects upwards, toward finding positive effects on young, low-skilled, black and Hispanic 
men.

\section{Results}

Figure 2 shows a local linear graph of the residuals from equation 1 for young, low-skilled black men. Time is recentered so that 0 is the effective date of a jurisdiction's BTB policy. For places without BTB, we recenter using the average effective date - October $2 0 1 0 \longdiv { 2 2 }$ Based on the pre-BTB period, the identifying assumption that BTB and non-BTB jurisdictions would evolve similarly in the absence of BTB - that is, that the treatment and control groups exhibit parallel trends - looks reasonable: the two lines follow each other closely before the date-zero threshold. After that date, however, the lines quickly diverge, with employment outcomes worsening in BTB-adopting places and improving slightly elsewhere. When we consider individuals who live in non-BTB places as a counterfactual for those who live in BTB-adopting places, it appears that BTB dramatically hurt employment outcomes for this group.

Figures 3 and 4 show equivalent graphs for Hispanic and white men, respectively. BTB appears to have a negative effect on Hispanic men, though the pre-trends for BTB and non-BTB areas are not as similar as they were for black men. That said, residuals hover around zero for both sets of jurisdictions before the policy change. They then fall for individuals treated by BTB, while they increase for those living in non-BTB locations. There is no apparent effect on white men.

To consider these outcomes more rigorously, Table 4 presents our main results for men ages 25-34 with no college degree. We consider the overall effect of BTB, and test for differential effects by race and ethnicity (black and Hispanic). We also present the total effect of BTB on these subgroups. Each column adds control variables from equation 1 and/or restricts the sample of analysis.

Column 1 shows the effects of BTB in the full sample, controlling only for MSA fixed effects. With no additional information about the individual or the time period, it appears that BTB reduces the average probability that low-skilled men are employed, by 5.0 percentage points. This effect is larger for black men, by 2.2 percentage points, and that difference is marginally significant. There

\footnotetext{
${ }^{22}$ To allow sufficient time on either side of the threshold in the graph, we use only jurisdictions where at least 18 months of data were available before and after the date of the policy change. This excludes approximately $20 \%$ of our sample, as a large number of jurisdictions adopted BTB in 2013 and 2014. However, the full sample is included in all regressions.
} 
is no differential effect on Hispanic men.

Column 2 adds detailed information about the individual, including age fixed effects, fixed effects for precise years of education, and whether they are currently enrolled in school. This reduces the magnitude of the above effects slightly, but qualitatively they are very similar.

Column 3 begins to add information about labor market trends, with time-by-region fixed effects; time is the month of the sample and region is the Census region. Controlling flexibly for labor market shocks is important, as our sample period (2004 through 2014) includes the Great Recession. Many BTB policies are implemented at the state-level, so we cannot control for month-specific state-level shocks. However, most of the non-BTB labor market shocks we are worried about, such as the housing crash, affected MSAs throughout the Census region. These fixed effects should absorb that type of variation 23

Controlling for time-by-region fixed effects wipes out the overall effect of BTB, reducing that coefficient to a small and statistically-insignificant negative 1 percentage point. However, the differentially-negative effect of BTB on black men remains: 2.2 percentage points (relative to a pre-BTB employment baseline for black men of $67.7 \%$ ). Combined with the coefficient on BTB, the total negative effect on black male employment is a statistically significant 3.2 percentage points $(p<0.01)$. There is no significant effect on Hispanic men in this specification.

Column 4 further controls for non-BTB labor market trends with MSA-specific linear time trends. This makes the estimate slightly more precise but has little effect on the estimates.

The effects of the controls and time trends might vary with race - for instance, the employment trend for black men in a particular MSA might be different from the trend for white men. Column 5 presents the results of a fully-interacted model, where the effects of all of the control variables in equation 1 are allowed to differ across race/ethnicity groups (white, black, and Hispanic). This reduces our statistical power substantially, but is the most conservative approach to isolating the effect of BTB. It is equivalent to running the regressions separately by race. Based on these estimates, BTB reduced employment for black men by a statistically-significant 3.4 percentage points (5.1\%), and for Hispanic men by a marginally-significant 2.3 percentage points $(2.9 \%)$. This is our preferred specification.

\footnotetext{
${ }^{23}$ Using (smaller) Census divisions instead of Census regions yields nearly identical results.
} 
One concern about using non-BTB jurisdictions as controls is that they tend to be less urban and have smaller black populations than places that adopt BTB. Even after controlling for pre-existing trends, they might not be good counterfactuals for the places likely to adopt BTB. Columns 6 and 7 restrict the sample to places that are similar to BTB-adopting labor markets.

Column 6 considers only individuals living in MSAs - that is, it excludes individuals living in more rural areas. (In our dataset, those individuals could still have been affected by state-level policies.) Since BTB-adopting jurisdictions tend to be more urban, perhaps it makes the most sense to compare them only with similarly-urban places. Under this restriction, we lose about onethird of our original sample. When we limit attention to individuals in or near cities, we lose some statistical power but the total effect on black and Hispanic men is similar to before: BTB reduces employment for black men by 2.9 percentage points $(p<0.05)$ and by 2.3 percentage points $(p<$ 0.10) for Hispanic men.

Column 7 restricts attention to only jurisdictions that adopted BTB by December 2014. If some types of places are more motivated to help ex-offenders or reduce racial disparities in employment, and thus to adopt BTB, labor market trends might be fundamentally different than they are in other places. This compares apples with apples, so to speak - we consider only individuals who live in places that eventually adopt BTB, and rely only on variation in the timing of policy adoption to identify BTB's effect. This reduces our sample to under half of what it was originally, so we again lose statistical power, but the magnitudes of the estimates are very similar to those in column 5 . BTB has no significant effect on white male employment, but reduces the probability of employment by 3.1 percentage points for black men $(p<0.05)$, and by 2.0 percentage points for Hispanic men (not statistically significant).

Overall, these results tell the same story as the graphs described above. It is reassuring to find such similar effects across most specifications and samples. In particular, our robustness samples including only metro areas or only BTB-adopting places show extremely similar effects. The fullyinteracted model is required to detect BTB's effect on Hispanic men, but that effect is also robust to different sample definitions. We see no significant effect of BTB on white men without college degrees in this age group. 


\subsection{Differential effects by region}

Given differences in racial composition and labor markets across the country, we might expect BTB to have different effects in different places. Table 5 separately considers the effects of BTB by Census region. To simplify presentation, we show the results separately by race, so the coefficients are comparable to the total effects (by race) in the fully-interacted model from column 5 above.

We see that young, low-skilled white men are not affected by BTB anywhere. However, the employment probabilities of their black peers are significantly reduced in three regions: the Northeast $(7.4 \%)$, the Midwest (7.5\%), and the West (8.8\%). The negative effect on black men is much smaller $(2.3 \%)$ and not statistically significant in the South, where a larger share of the population is black 24

Similarly, we see evidence of differential effects for Hispanic men, though limited statistical power means that none of the coefficients are statistically significant. The coefficients are negative across all four regions, but are much larger in the Northeast (3.5\%), the Midwest (5.7\%), and the South (3.6\%). The estimated effect for Hispanic men living in the West - where a larger share of the population is Hispanic - is near zero 25

These results suggest that the larger the black or Hispanic population, the less likely employers are to use race/ethnicity as a proxy for criminality.

\subsection{BTB in weak vs. strong labor markets}

Employers might be quicker to exclude large categories of job applicants - such as those with criminal records, or young black men - when they have many applicants to choose from than when it is relatively difficult to find qualified employees. We therefore might expect a policy like BTB to have larger negative effects on the employment of young, low-skilled black and Hispanic men when the unemployment rate is high than when it is low. Table 6 adds terms that allow the effect of BTB to vary with the national unemployment rate. (We use the national unemployment rate rather than state or local unemployment rates to limit concerns about reverse causality.) Effects

\footnotetext{
${ }^{24}$ Based on 2010 Cenus data, $19 \%$ of the population in the South is black, compared with $12 \%$ in the Northeast, $10 \%$ in the Midwest, and $5 \%$ in the West (Rastogi et al. 2011).

${ }^{25}$ Based on 2010 Cenus data, $29 \%$ of the population in the West is Hispanic, compared with $13 \%$ in the Northeast, $7 \%$ in the Midwest, and $16 \%$ in the South (Ennis et al., 2011).
} 
are shown separately by race (equivalent to the total effects estimated in column 5 in Table 4 ).

Columns 1 and 2 show the effect on white men, including linear and quadratic functions of the unemployment rate, respectively. The total effects of BTB are calculated at 5\%,6\%,7\%,8\% and 9\% national unemployment. (During this period, the unemployment rate ranged from $4.4 \%$ to $10.0 \%$.) The effect of the policy is slightly positive when unemployment is low, and slightly negative when unemployment is high, but at all unemployment rates the effect of BTB on white men is near-zero and statistically insignificant.

Columns 3 and 4 show the effect on black men. Again the effect of BTB is more negative when unemployment is high, but now the estimated total effects are relatively large and negative even at low unemployment. The negative total effect becomes statistically significant at $7 \%$ or $8 \%$ unemployment, and at $9 \%$ unemployment the total effect of BTB on black men is over 3.6 percentage points and statistically significant $(p<0.05)$.

Columns 5 and 6 show the effect on Hispanic men. The same pattern emerges: the total effect of the policy is more negative as the unemployment rate rises, and that effect becomes statistically significant when unemployment reaches $7 \%$ or $8 \%$. With the quadratic term included, the total effect of BTB on Hispanic men is near-zero and statistically insignificant at 5\% unemployment, but reaches $-3.2 \%(p<0.05)$ at $9 \%$ unemployment.

These results confirm that employers are more likely to statistically discriminate when the supply of labor greatly exceeds the demand for it. They also suggest that BTB policies may have worsened the effect of the recent recession for these disadvantaged groups.

\subsection{Substitution to other groups}

BTB has the predicted effects on the group most directly affected by the policy, decreasing the probability of employment for young, low-skilled black and Hispanic men. Other groups might also be affected, as the beneficiaries of statistical discrimination. In particular, we might expect employers to prefer groups that are less likely to include recently-incarcerated offenders, such as older applicants, those with college degrees, women, and/or white applicants. However, it is also possible that increasing the asymmetric information problem in this labor market could reduce total employment. 
Table 7 presents the results of a fully-interacted model (equivalent to column 5 in Table 4 above) for other demographic groups.

Column 1 considers men ages 25-34 with college degrees. This group is far less likely to include individuals with criminal records, so employers might be more willing to interview them after BTB removes criminal history information from job applications. However, college-educated men are unlikely to be interested in low-skilled jobs. We see that the effect of BTB on employment in this group is very small and statistically insignificant.

Column 2 considers the effect of BTB on older working-age men, ages 35-64, with no high school diploma. These men are still more likely to have a criminal record, but are much less likely than younger men to have been recently incarcerated and/or to still be actively engaged in criminal behavior or associating with people who are. A previous criminal conviction might therefore be less worrisome for a potential employer. We see that this is the case with respect to black men: on average, BTB increases their employment by 4.3 percentage points $(9.4 \%)$, though this effect is not statistically significant. However, the effect on Hispanic men is negative and about as large as before: 2.8 percentage points $(3.9 \%)$.

Column 3 considers the effect for older men (age 35-64) with no college degree - our preferred definition of "low-skilled". Here we see that BTB increases black male employment by a statistically significant 2.8 percentage points $(4.3 \%)$. The effect on Hispanic men is also positive (1.5 percentage points, which is $1.9 \%$ of the pre-BTB baseline) but not statistically significant. This suggests that employers are weighting age more heavily when they consider job applicants, substituting away from young black and Hispanic men and toward older black (and possibly Hispanic) men of the same educational level, to avoid hiring the more worrisome ex-offenders.

Column 4 considers the effect on older men with a college degree. As for highly-educated younger men, we see no effects here.

Column 5 considers young (age 25-34) women with no high school diploma. Women are less likely than men to have a criminal record, and particularly less likely to commit violent crime. If violent behavior is a primary concern for employers, we might see substitution into this group. However, female employment might also respond to male partners' inability to find a job, so an increase in employment might tell us more about intrahousehold responses than employers' pref- 
erence. There is some evidence that white women are more likely to work when BTB is in effect (employment increases by 1.2 percentage points, $2.6 \%$ of the baseline), and that black women work less (employment decreases by 2.9 percentage points, $6.4 \%$ of the baseline), but neither effect is statistically significant.

Column 6 considers young women with no college degree. There are no significant effects here, although Hispanic women in this group seem to benefit slightly, on average.

Column 7 considers young women with a college degree. BTB increases employment by a statistically significant 3.2 percentage points (3.9\%) for black women in this group. Given that college-educated women and men without college degrees are likely working in different labor markets, this probably reflects intrahousehold substitution of labor rather than employers' preference for hiring women due to BTB.

\subsection{Persistence of effects over time}

It's possible that BTB increases the expected cost of hiring low-skilled black and Hispanic men such that the policy permanently lowers employment for these groups. Alternatively, we might expect BTB to have a temporary effect if employers and workers eventually adapt to the policy and return to the pre-BTB equilibrium. For instance, employers might figure out new ways to screen job applicants, and workers might learn new ways to signal their job-readiness to employers.

Table 8 shows the cumulative effects of BTB on employment over time, for young, low-skilled white, black, and Hispanic men, respectively. The coefficients show the effect of BTB during the first year, the second year, the third year, and four or more years after the policy went into effect.

Across all years, BTB's effect on white men is near-zero and statistically insignificant. However, BTB's effect on black men is large and grows over time. BTB reduces employment for black men by 2.7 percentage points (not statistically significant) during the first year, 5.1 percentage points $(p<$ $0.01)$ during the second year, 4.1 percentage points $(p<0.10)$ during the third year, 8.4 percentage points $(p<0.01)$ during the fourth year, and an average of 7.7 percentage points $(p<0.05)$ during the fifth and later years. This suggests that BTB has a permanent effect on employment for black men.

Effects on Hispanic men tell a slightly different story: BTB reduces employment for this group 
by 1.6 percentage points (not statistically significant) during the first year after the policy goes into effect, by 3.0 percentage points $(p<0.10)$ during the second year, and by 2.6 percentage points (not statistically significant) during the third year. However, after the third year the effect declines to near-zero. It appears that young Hispanic men adapt to the policy over time, perhaps by using their networks to find jobs and signal their job-readiness to employers. This is consistent with previous evidence that labor market networks play a particularly important role in hiring for low-skilled Hispanics (Hellerstein et al., 2011).

\section{Robustness}

\subsection{Effects on young men without a high school diploma}

In the above analyses, we define "low-skilled" as having no college degree, for two reasons: (1) this group includes the vast majority of ex-offenders, and (2) it provides sufficient sample size to draw sound conclusions. However, we expect effects to be larger in magnitude for the subset of that population with less education.

Table A-3 presents the main results for those without a high school diploma or GED. The total effects of BTB on black and Hispanic men are indeed larger in magnitude, but imprecisely estimated due to the relatively small sample. Our preferred specification (column 5) estimates that BTB reduces employment for black men by 14.9 percentage points (33\% of the baseline); the $95 \%$ confidence interval suggests that this negative effect could range from 7.2 percentage points (16\%) to 22.5 percentage points (50\%). For Hispanic men we estimate that BTB reduces employment by 9.5 percentage points $(13 \%)$; the $95 \%$ confidence interval suggests this negative effect could range from 4.2 percentage points $(5.8 \%)$ to 14.8 percentage points $(20 \%)$.

We also find suggestive evidence that BTB has a positive effect on white men with no high school diploma. On average, white men in this group are 3.9 percentage points $(5.6 \%)$ more likely to be employed after BTB than before, but this effect is not statistically significant. 


\subsection{Effects of individual states on the main estimates}

The implementation and effects of BTB could vary across states, and particular states might be driving our main results. Looking at effects by region provides some evidence on this issue, but we now focus on the effects of individual states. Tables A-4 and A-5 reproduce column 5 from Table 4, dropping each state, in turn. Across the board, the results are qualitatively consistent with our main results, but there are some states that have particularly strong effects on the estimates. Excluding Colorado or New Jersey, for instance, increases the magnitude and statistical significance of the effect on Hispanic men, suggesting those states are outliers. Dropping Virginia increases the magnitude and statistical significance of the effect on black men, while dropping DC or South Carolina reduces the magnitude of that effect slightly.

\section{Discussion}

"Ban the box" has arisen as a popular policy aimed at helping ex-offenders find jobs, with a related goal of decreasing racial disparities in employment. However, BTB does not address employers' concerns about hiring those with criminal records, and so could increase discrimination against groups that are more likely to include recently-incarcerated ex-offenders - particularly young, lowskilled black and Hispanic men.

In this paper, we exploit the variation in adoption and timing of state and local BTB policies to estimate BTB's effects on employment for these groups. We find that BTB reduces the probability of employment for young black men without a college degree by 3.4 percentage points (5.1\%), and for young Hispanic men without a college degree by 2.3 percentage points $(2.9 \%)$. The effect on black men is particularly robust across different specifications and samples.

These effect sizes may seem large but they are consistent with those found in related studies. Holzer et al. (2006) found that the last hire was 37\% more likely to be a black man when firms conducted criminal background checks, while Bartik and Nelson (2016) found that banning credit history checks reduced the likelihood of finding a job by $7-16 \%$ for black job-seekers. Given relatively high turnover rates in the low-skilled labor market ${ }^{26}$ it does not take long for increases or decreases

\footnotetext{
${ }^{26}$ Based on data from the Job Openings and Labor Turnover Survey (JOLTS), industries with high proportions of low-skilled jobs, such as construction, retail trade, and hospitality services, have monthly separations hovering around
} 
in hiring rates to result in a large change in employment. For instance, in a similar context Wozniak (2015) found that allowing drug testing by employers increased employment for black men by 7-30\%.

In light of these other studies and estimated turnover rates, our estimates are plausible and may actually be somewhat small. Indeed, our effects are likely biased upwards (toward finding positive effects of BTB) for two reasons: (1) Jurisdictions that adopt BTB are typically more motivated to help ex-offenders find jobs, and this motivation alone should increase employment for those with criminal records. (2) The CPS excludes individuals who are incarcerated, so if some of the men who are unemployed as a result of BTB commit crime and are sent to prison, they will end up not being included in our sample.

This is the first paper to consider the effects of BTB on the employment of young, low-skilled black and Hispanic men, but our findings are consistent with theory and other research about statistical discrimination in employment. There is rapidly-increasing evidence that BTB has unintentionally done more harm than good when it comes to helping disadvantaged job-seekers find jobs. Increasing employment rates for ex-offenders is a top policy priority, for good reason, but policymakers cannot simply wish away employers' concerns about hiring those with criminal records. Policies that directly address those concerns - for instance, by providing more information about job applicants with records, or improving the average ex-offender's job-readiness - could have greater benefits without the unintended consequences found here.

\section{References}

Agan, A. and Starr, S. (2016). Ban the box, criminal records, and statistical discrimination: A field experiment. University of Michigan Law and Economics Research Paper No. 16-012.

Akerlof, G. (1970). The market for "lemons": Quality uncertainty and the market mechanism. Quarterly Journal of Economics, 84(3):488-500.

5-6\% of total employment. (Data are unavailable by age and skill level, so this likely underestimates the degree of turnover for our population of interest.) If we conservatively assume (1) a $5.5 \%$ monthly separation rate for the jobs held by young, low-skilled black men, and (2) that BTB reduces hiring rates for this population by $7 \%$, then we would expect a $5 \%$ reduction in employment within 14 months. This is in line with our results from Table 8 
Autor, D. H. and Scarborough, D. (2008). Does job testing harm minority workers? evidence from retail establishments. Quarterly Journal of Economics, 123(1):219-277.

Bartik, A. W. and Nelson, S. T. (2016). Credit reports as resumes: The incidence of pre-employment credit screening. MIT Economics Working Paper Number 16-01.

Becker, G. S. (1968). Crime and punishment: An economic approach. The Journal of Political Economy, pages 169-217.

Bonczar, T. P. (2003). Prevalence of imprisonment in the u.s. population, 1974-2001. Bureau of Justice Statistics NCJ 197976.

Borjas, G. J. (2015). The wage impact of the Marielitos: A reappraisal. Industrial \& Labor Relations Review, forthcoming.

Bushway, S. D. (2004). Labor market effects of permitting employer access to criminal history records. Journal of Contemporary Criminal Justice, 20:276-291.

Card, D. (1990). The impact of the Mariel boatlift on the Miami labor market. Industrial \& Labor Relations Review, 43(2):245-257.

Carson, E. A. and Golinelli, D. (2014). Prisoners in 2012: Trends in admissions and releases, 1991-2012. Bureau of Justice Statistics NCJ 243920.

Cooper, A. D., Durose, M. R., and Snyder, H. N. (2014). Recidivism of prisoners released in 30 states in 2005: Patterns from 2005 to 2010. Bureau of Justice Statistics, NCJ 244205. Available at http://www.bjs.gov/index.cfm?ty=pbdetail\&iid=4986.

CPS (2016). About the Current Population Survey. Available at http://www.census.gov/ programs-surveys/cps/about.html.

Ennis, S. R., Rios-Vargas, M., and Albert, N. G. (2011). The Hispanic Population: 2010. 2010 Census Brief. 
Finlay, K. (2009). Effect of employer access to criminal history data on the labor market outcomes of ex-offenders and non-offenders. In Autor, D. H., editor, Studies of Labor Market Intermediation, pages $89-125$.

Google (2016). Google transparency report: Frequently asked questions. Available at https: //wWw.google.com/transparencyreport/removals/europeprivacy/faq/?hl=en.

Hainmueller, J. (2012). Entropy balancing for causal effects: A multivariate reweighting method to produce balanced samples in observational studies. Political Analysis, 20(1):25-46.

Hellerstein, J. K., McInerney, M., and Neumark, D. (2011). Neighbors and coworkers: The importance of residential labor market networks. Journal of Labor Economics, 20(4):659-695.

Holzer, H. J., Raphael, S., and Stoll, M. A. (2004). The effect of an applicant's criminal history on employer hiring decisions and screening practices: Evidence from los angeles. National Poverty Center Working Paper Number 04-15, University of Michigan.

Holzer, H. J., Raphael, S., and Stoll, M. A. (2006). Perceived criminality, criminal background checks, and the racial hiring practices of employers. Journal of Law and Economics, 49:451-480.

Justice Center (2016). NRRC Facts \& Trends. Available at https://csgjusticecenter.org/nrrc/ facts-and-trends/.

Kearney, M. S., Harris, B. H., Jacome, E., and Parker, L. (2014). Ten economic facts about crime and incarceration in the united states. The Hamilton Project.

Meyer, B. D., Mok, W. K. C., and Sullivan, J. X. (2015). Household surveys in crisis. Journal of Economic Perspectives, 29(4):199-226.

Pager, D. (2003). The mark of a criminal record. American Journal of Sociology, 108(5):937-975.

Rastogi, S., Johnson, T. D., Hoeffel, E. M., and Jr., M. P. D. (2011). The black population: 2010. 2010 Census Brief.

Schnepel, K. (2015). Good jobs and recidivism. Economic Journal, forthcoming. 
Shoag, D. and Veuger, S. (2016). No woman no crime: Ban the box, employment, and upskilling. AEI Working Paper.

Starr, S. (2015). Do ban-the-box laws reduce employment barriers for black men? Unpublished conference draft.

Stoll, M. A. (2009). Ex-offenders, criminal background checks, and racial consequences in the labor market. University of Chicago Legal Forum, pages 381-419.

Thomas, M. (2016). The impact of mandated maternity benefits of the gender differential in promotions: Examining the role of adverse selection. Working paper.

Wolff, N. and Shi, J. (2012). Childhood and adult trauma experiences of incarcerated persons and their relationship to adult behavioral health problems and treatment. International Journal of Environmental Research and Public Health, 9:1908-1926.

Wozniak, A. (2015). Discrimination and the effects of drug testing on black employment. Review of Economics and Statistics, 97(3):548-566.

Yang, C. (2016). Local labor markets and criminal recidivism. Working paper.

Zhao, Q. and Percival, D. (2016). Entropy balancing is doubly robust. Stanford Working Paper. 


\section{Figures and Tables}

Figure 1: Jurisdictions with BTB policies by December 2014

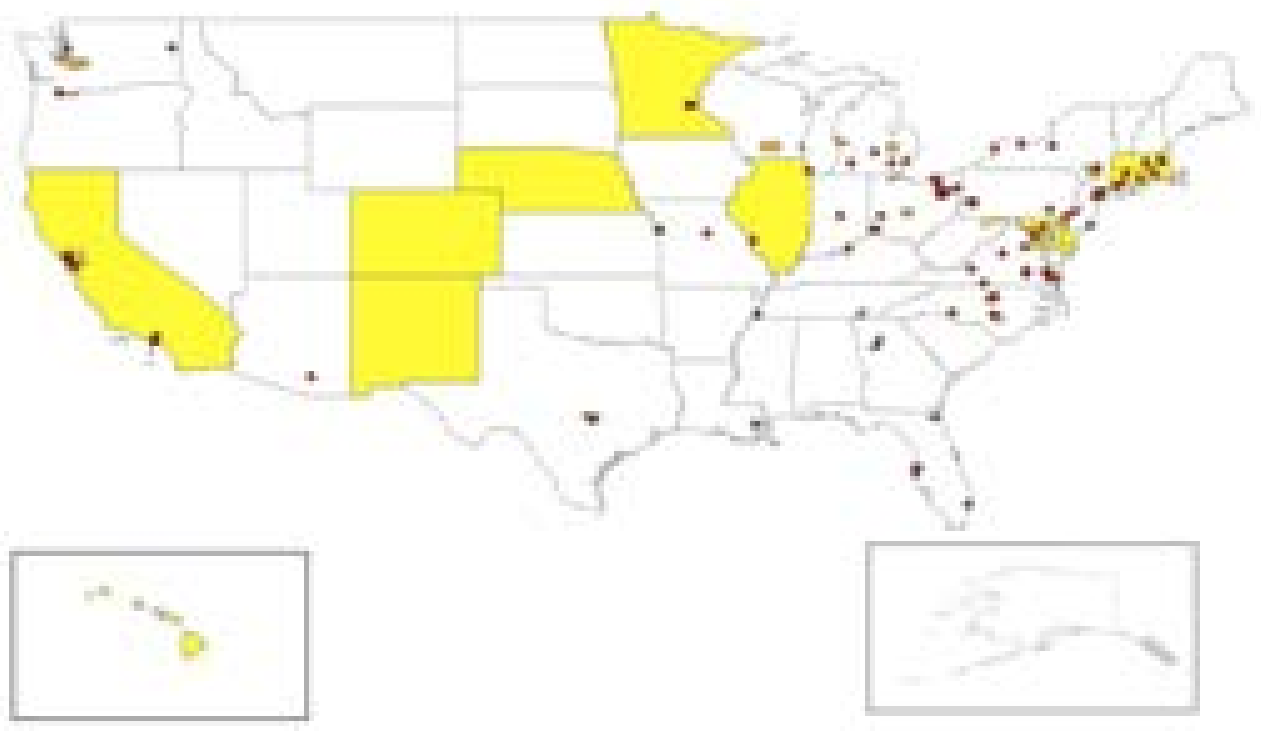

Jurisdictions with BTB policies are represented by yellow shading (state-level policies), orange shading (county-level policies), and red dots (city-level policies.) 
Figure 2: Effect of BTB on probability of employment for black men ages 25-34, no college degree

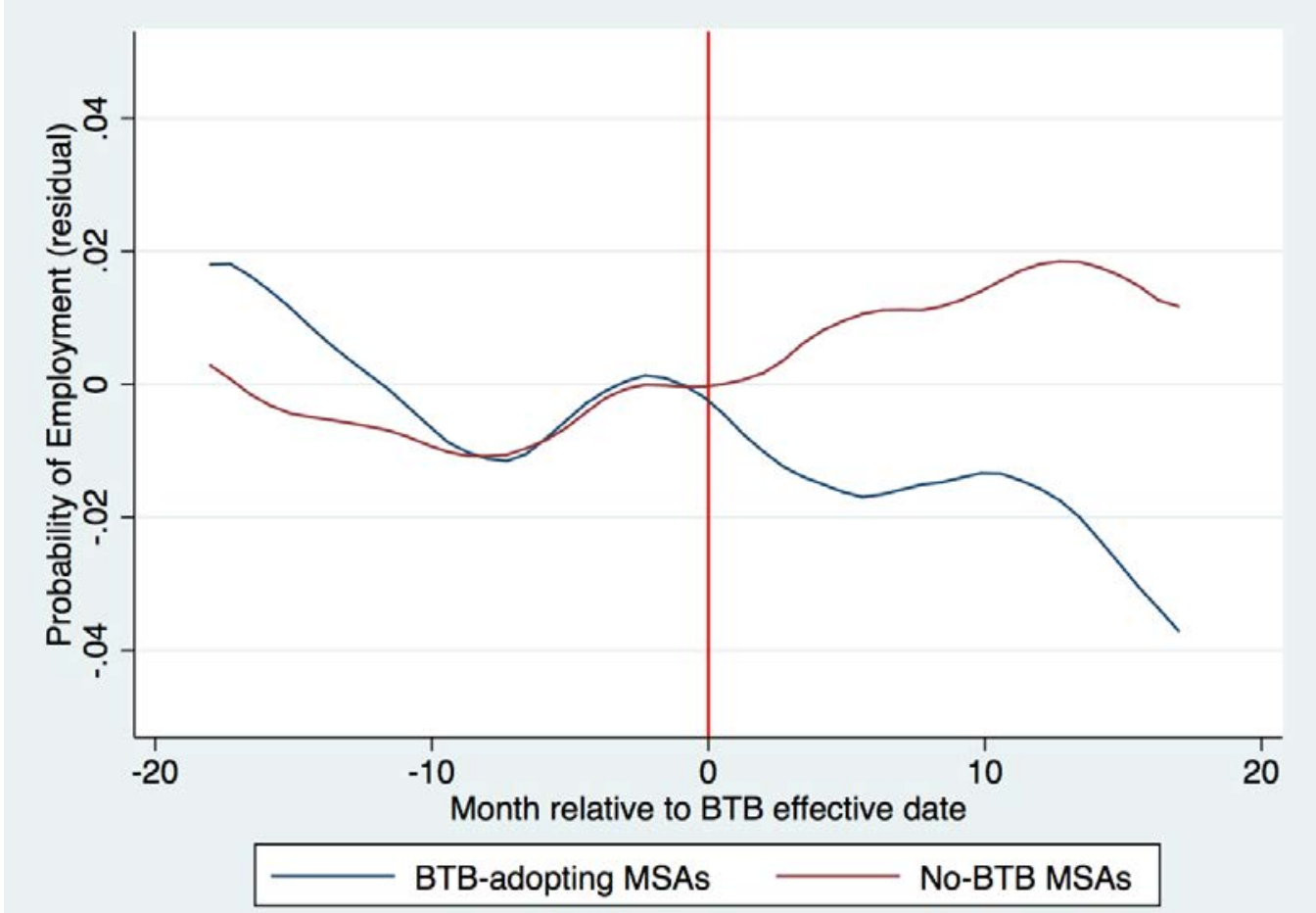

Data source: CPS 2004-2014. Sample includes black men ages 25-34 who do not have a college degree. To allow at least 18 months of data before and after the effective date, this graph is limited to jurisdictions that implemented BTB between June 2005 and July 2013. The mean of the effective dates applying to this group for BTB-adopting jurisdictions in this window - October 2010 - is used as the "effective date" for the no-BTB jurisdictions. 
Figure 3: Effect of BTB on probability of employment for Hispanic men ages 25-34, no college degree

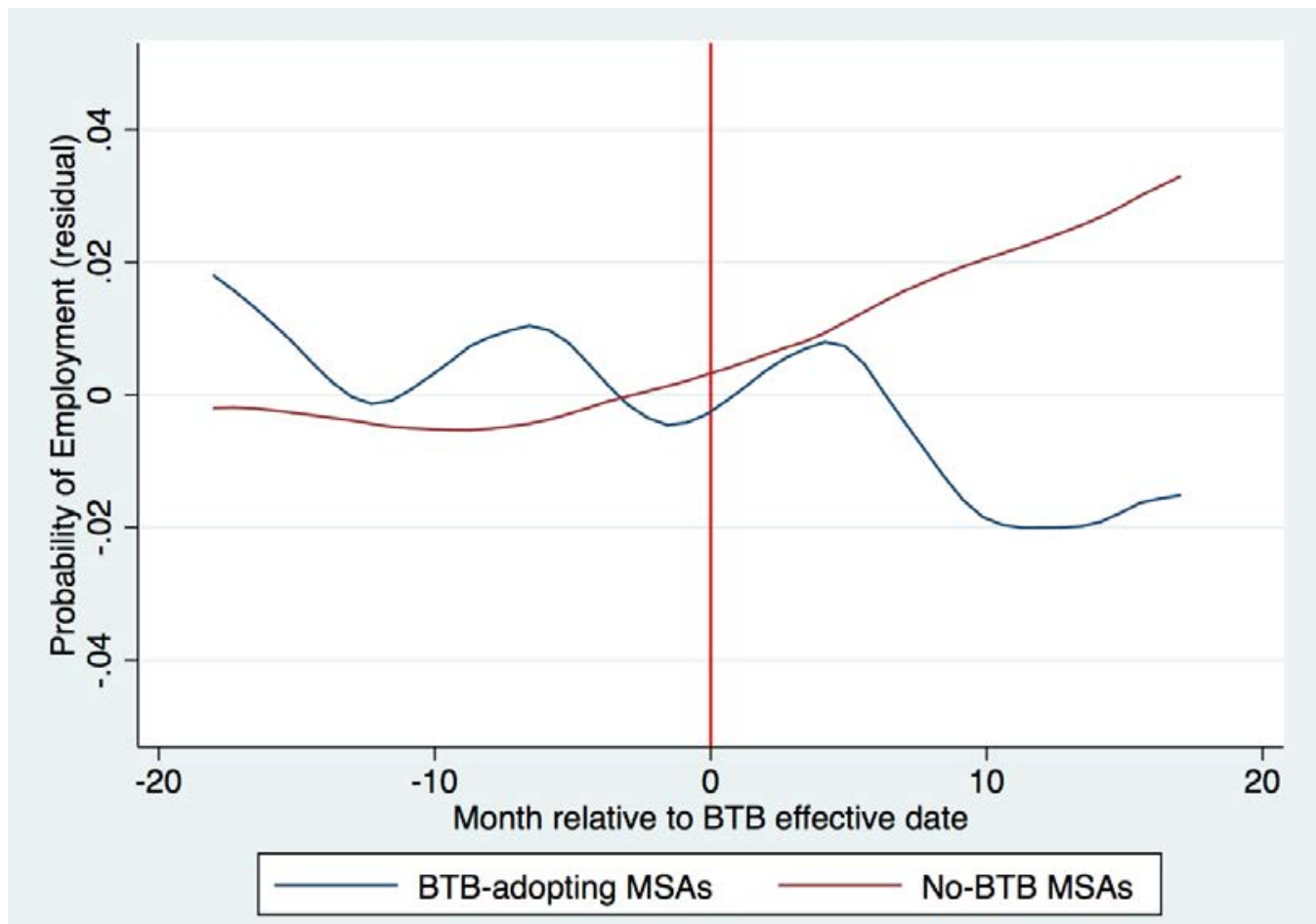

Data source: CPS 2004-2014. Sample includes Hispanic men ages 25-34 who do not have a college degree. To allow at least 18 months of data before and after the effective date, this graph is limited to jurisdictions that implemented BTB between June 2005 and July 2013. The mean of the effective dates applying to this group for BTB-adopting jurisdictions in this window - May 2010 - is used as the "effective date" for the no-BTB jurisdictions. 
Figure 4: Effect of BTB on probability of employment for white men ages 25-34, no college degree

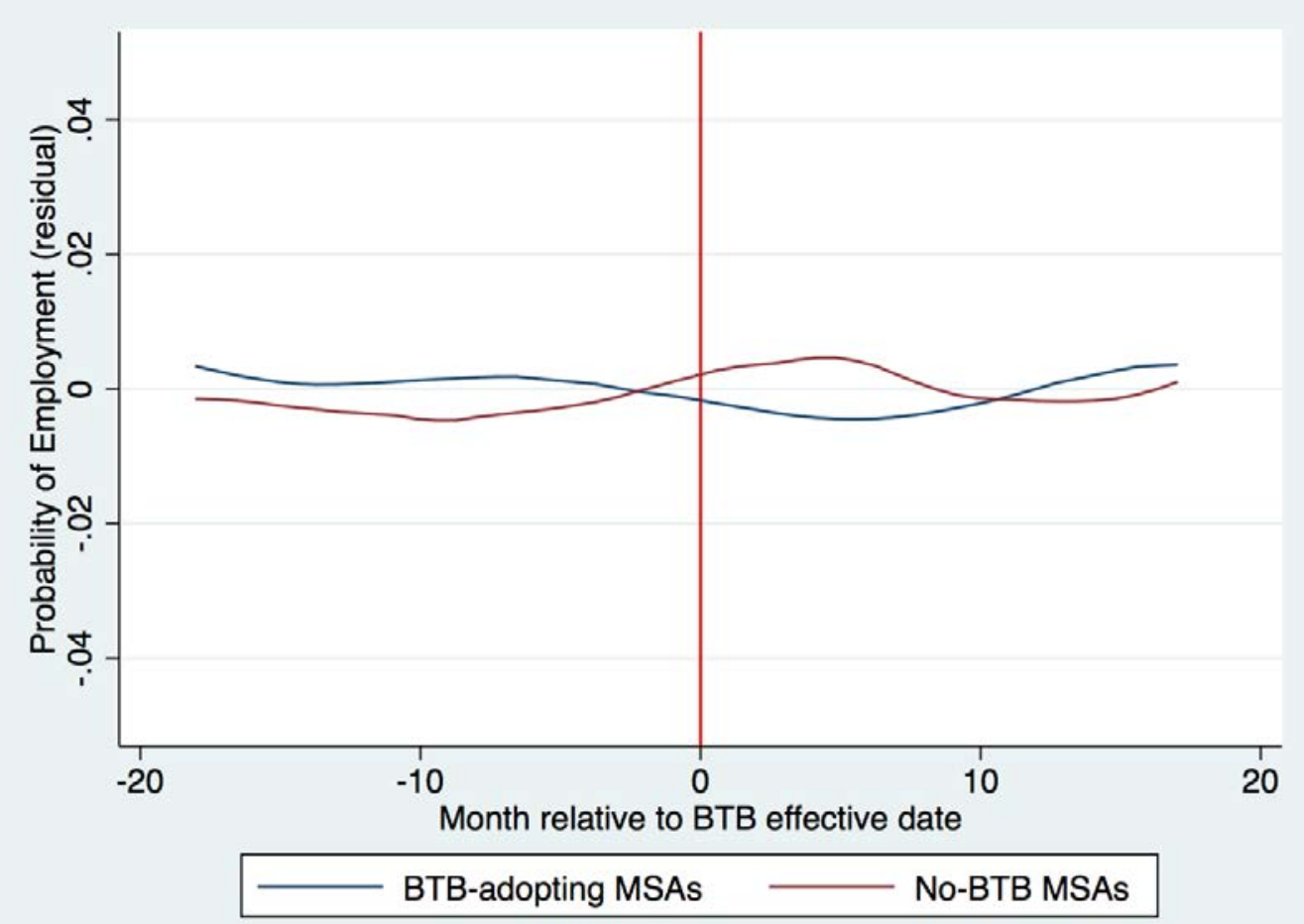

Data source: CPS 2004-2014. Sample includes white, non-Hispanic men ages 25-34 who do not have a college degree. To allow at least 18 months of data before and after the effective date, this graph is limited to jurisdictions that implemented BTB between June 2005 and July 2013. The mean of the effective dates applying to this group in BTB-adopting jurisdictions in this window May 2010 - is used as the "effective date" for the no-BTB jurisdictions. 
Table 1: Summary Statistics

\begin{tabular}{lcccc}
\hline \hline & \multicolumn{2}{c}{ Men ages 25-34 } & \multicolumn{2}{c}{ Men ages 35-64 } \\
& Mean & $(\mathrm{SD})$ & Mean & $(\mathrm{SD})$ \\
\hline BTB & 0.1930 & $(0.3946)$ & 0.1870 & $(0.3899)$ \\
Employed & 0.8335 & $(0.3725)$ & 0.8026 & $(0.3981)$ \\
No HS diploma or GED & 0.0769 & $(0.2665)$ & 0.0847 & $(0.2784)$ \\
No college degree & 0.5883 & $(0.4921)$ & 0.5804 & $(0.4935)$ \\
College degree or more & 0.4117 & $(0.4921)$ & 0.4196 & $(0.4935)$ \\
Enrolled in school & 0.0145 & $(0.1196)$ & 0.0023 & $(0.0478)$ \\
Age & 29.492 & $(2.8835)$ & 48.930 & $(8.0649)$ \\
White & 0.7934 & $(0.4048)$ & 0.8399 & $(0.3667)$ \\
Black & 0.0965 & $(0.2953)$ & 0.0893 & $(0.2851)$ \\
Hispanic & 0.1100 & $(0.3129)$ & 0.0709 & $(0.2566)$ \\
Northeast & 0.1881 & $(0.3908)$ & 0.2154 & $(0.4111)$ \\
Midwest & 0.2563 & $(0.4366)$ & 0.2526 & $(0.4345)$ \\
South & 0.3155 & $(0.4647)$ & 0.3118 & $(0.4632)$ \\
West & 0.2401 & $(0.4271)$ & 0.2202 & $(0.4144)$ \\
Metro area & 0.7089 & $(0.4543)$ & 0.6819 & $(0.4657)$ \\
\hline N & 855,772 & $2,873,182$ \\
\hline \hline
\end{tabular}

Data source: 2004-2014 Current Population Survey. 
Table 2: Summary Statistics: Men ages 25-34 with no college degree

\begin{tabular}{|c|c|c|c|}
\hline & All & Never adopted BTB & Adopted BTB \\
\hline \multicolumn{4}{|l|}{ White Non-Hispanic } \\
\hline BTB & $0.1414(0.3484)$ & $0(0)$ & $0.3408(0.4740)$ \\
\hline Employed & $0.8087(0.3933)$ & $0.8110(0.3915)$ & $0.8055(0.3958)$ \\
\hline No HS diploma or GED & $0.1094(0.3121)$ & $0.1198(0.3247)$ & $0.0947(0.2927)$ \\
\hline Enrolled in school & $0.0115(0.1068)$ & $0.0099(0.0989)$ & $0.0139(0.1169)$ \\
\hline Age & $29.424(2.8935)$ & $29.433(2.8886)$ & $29.411(2.9003)$ \\
\hline Northeast & $0.1883(0.3910)$ & $0.1583(0.3651)$ & $0.2307(0.4213)$ \\
\hline Midwest & $0.2873(0.4525)$ & $0.2513(0.4338)$ & $0.3380(0.4730)$ \\
\hline South & $0.2909(0.4542)$ & $0.3541(0.4782)$ & $0.2017(0.4013)$ \\
\hline West & $0.2335(0.4231)$ & $0.2362(0.4248)$ & $0.2297(0.4206)$ \\
\hline Metro area & $0.6127(0.4871)$ & $0.4261(0.4945)$ & $0.8760(0.3295)$ \\
\hline $\mathrm{N}$ & 373,237 & 218,413 & 154,824 \\
\hline \multicolumn{4}{|l|}{ "Black Non-Hispanic } \\
\hline BTB & $0.2006(0.4005)$ & $0(0)$ & $0.3481(0.4764)$ \\
\hline Employed & $0.6564(0.4749)$ & $0.6588(0.4741)$ & $0.6547(0.4755)$ \\
\hline No HS diploma or GED & $0.1498(0.3569)$ & $0.1659(0.3720)$ & $0.1380(0.3449)$ \\
\hline Enrolled in school & $0.0132(0.1143)$ & $0.0122(0.1097)$ & $0.0140(0.1175)$ \\
\hline Age & $29.371(2.9194)$ & $29.419(2.8761)$ & $29.336(2.9504)$ \\
\hline Northeast & $0.1228(0.3283)$ & $0.0405(0.1971)$ & $0.1834(0.3870)$ \\
\hline Midwest & $0.1898(0.3921)$ & $0.0930(0.2905)$ & $0.2609(0.4392)$ \\
\hline South & $0.5916(0.4915)$ & $0.7943(0.4042)$ & $0.4427(0.4967)$ \\
\hline West & $0.0957(0.2942)$ & $0.0722(0.2587)$ & $0.1130(0.3166)$ \\
\hline Metro area & $0.8174(0.3864)$ & $0.6110(0.4875)$ & $0.9690(0.1733)$ \\
\hline $\mathrm{N}$ & 59,872 & 25,363 & 34,509 \\
\hline \multicolumn{4}{|l|}{ Hispanic } \\
\hline BTB & $0.2687(0.4433)$ & $0(0)$ & $0.4435(0.4968)$ \\
\hline Employed & $0.7921(0.4058)$ & $0.8138(0.3893)$ & $0.7779(0.4156)$ \\
\hline No HS diploma or GED & $0.2283(0.4198)$ & $0.2481(0.4319)$ & $0.2154(0.4111)$ \\
\hline Enrolled in school & $0.0149(0.1211)$ & $0.0141(0.1178)$ & $0.0154(0.1232)$ \\
\hline Age & $29.303(2.8739)$ & $29.251(2.8762)$ & $29.338(2.8719)$ \\
\hline Northeast & $0.1376(0.3445)$ & $0.0394(0.1946)$ & $0.2014(0.4011)$ \\
\hline Midwest & $0.1065(0.3084)$ & $0.0856(0.2798)$ & $0.1200(0.3250)$ \\
\hline South & $0.2983(0.4575)$ & $0.5669(0.4955)$ & $0.1236(0.3291)$ \\
\hline West & $0.4577(0.4982)$ & $0.3081(0.4617)$ & $0.5550(0.4970)$ \\
\hline Metro area & $0.8394(0.3672)$ & $0.7058(0.4557)$ & $0.9262(0.2614)$ \\
\hline $\mathrm{N}$ & 70,310 & 27,710 & 42,600 \\
\hline
\end{tabular}

Data source: 2004-2014 Current Population Survey. Standard errors in parentheses. 
Table 3: Ban the Box policies implemented by December 2014

\begin{tabular}{|c|c|c|c|}
\hline State & Jurisdiction & Law Type & Start Date \\
\hline \multirow[t]{15}{*}{ California } & State & Public & June 25,2010 \\
\hline & Alameda County & Public & March 1, 2007 \\
\hline & Berkeley & Public & October 1,2008 \\
\hline & Carson City & Public & March 6, 2012 \\
\hline & Compton & Public & July 1, 2011 \\
\hline & Compton & Contract & July 1, 2011 \\
\hline & East Palo Alto & Public & January 1, 2005 \\
\hline & Oakland & Public & January 1, 2007 \\
\hline & Pasadena & Public & July 1, 2013 \\
\hline & Richmond & Public & November 22, 2011 \\
\hline & Richmond & Contract & July 30, 2013 \\
\hline & Santa Clara & Public & May 1, 2012 \\
\hline & San Francisco & Public & October 11, 2005 \\
\hline & San Francisco & Contract & April 4, 2014 \\
\hline & San Francisco & Private & April 4, 2014 \\
\hline Colorado & State & Public & August 8, 2012 \\
\hline \multirow[t]{5}{*}{ Connecticut } & State & Public & October 1, 2010 \\
\hline & Bridgeport & Public & October 5, 2009 \\
\hline & Hartford & Public & June 12, 2009 \\
\hline & New Haven & Public & February 1, 2009 \\
\hline & Norwich & Public & December 1, 2008 \\
\hline District of Columbia & Washington & Public & January 1, 2011 \\
\hline \multirow[t]{3}{*}{ Delaware } & State & Public & May 8, 2014 \\
\hline & Wilmington & Public & December 10, 2012 \\
\hline & New Castle County & Public & January 28, 2014 \\
\hline \multirow[t]{3}{*}{ Florida } & Jacksonville & Public & November 10, 2008 \\
\hline & Pompano Beach & Public & December 1, 2014 \\
\hline & Tampa & Public & January 14, 2013 \\
\hline \multirow[t]{2}{*}{ Georgia } & Atlanta & Public & January 1, 2013 \\
\hline & Fulton County & Public & July 16, 2014 \\
\hline \multirow[t]{3}{*}{ Hawaii } & State & Public & January 1, 1998 \\
\hline & State & Contract & January 1, 1998 \\
\hline & State & Private & January 1, 1998 \\
\hline \multirow[t]{6}{*}{ Illinois } & State & Public & January 1, 2014 \\
\hline & State & Contract & July 19, 2014 \\
\hline & State & Private & July 19, 2014 \\
\hline & Chicago & Public & June 6,2007 \\
\hline & Chicago & Contract & November 5, 2014 \\
\hline & Chicago & Private & November 5, 2014 \\
\hline Indiana & Indianapolis & Public & May 25, 2014 \\
\hline Kentucky & Louisville & Public & March 13, 2014 \\
\hline \multirow[t]{2}{*}{ Kansas } & Kansas City & Public & November 6, 2014 \\
\hline & Wyandotte County & Public & November 6, 2014 \\
\hline Louisiana & New Orleans & Public & January 10, 2014 \\
\hline \multirow[t]{5}{*}{ Maryland } & State & Public & October 1, 2013 \\
\hline & Baltimore & Public & December 1, 2007 \\
\hline & Baltimore & Contract & April 1, 2014 \\
\hline & Baltimore & Private & April 1, 2014 \\
\hline & Prince George's County & Public & December 4, 2014 \\
\hline \multirow[t]{5}{*}{ Massachusetts } & State & Public & August 6, 2010 \\
\hline & Boston & Public & July 1, 2006 \\
\hline & Cambridge & Public & May 1, 2007 \\
\hline & Cambridge & Contract & January 28, 2008 \\
\hline & Worcester & Public & June 23, 2009 \\
\hline \multirow[t]{2}{*}{ Michigan } & Ann Arbor & Public & May 5, 2014 \\
\hline & Detroit & Public & September 13, 2010 \\
\hline
\end{tabular}


Table 3: (continued)

\begin{tabular}{|c|c|c|c|}
\hline State & Jurisdiction & Law Type & Start Date \\
\hline & Detroit & Contract & June 1, 2012 \\
\hline & East Lansing & Public & April 15, 2014 \\
\hline & Genesee County & Public & June 1, 2014 \\
\hline & Kalamazoo & Public & January 1, 2010 \\
\hline & Muskegon & Public & January 12, 2012 \\
\hline \multirow[t]{5}{*}{ Minnesota } & State & Public & January 1, 2009 \\
\hline & State & Contract & January 1, 2009 \\
\hline & State & Private & May 13, 2013 \\
\hline & Minneapolis & Public & December 1, 2006 \\
\hline & St. Paul & Public & December 5, 2006 \\
\hline \multirow[t]{5}{*}{ Missouri } & Columbia & Public & December 1, 2014 \\
\hline & Columbia & Contract & December 1, 2014 \\
\hline & Columbia & Private & December 1, 2014 \\
\hline & Kansas City & Public & April 4, 2013 \\
\hline & St. Louis & Public & October 1, 2014 \\
\hline Nebraska & State & Public & April 16, 2014 \\
\hline \multirow[t]{5}{*}{ New Jersey } & Atlantic City & Public & December 23, 2011 \\
\hline & Atlantic City & Contact & December 23, 2011 \\
\hline & Newark & Public & September 19, 2012 \\
\hline & Newark & Contract & September 19, 2012 \\
\hline & Newark & Private & September 19, 2012 \\
\hline New Mexico & State & Public & March 8, 2010 \\
\hline \multirow[t]{10}{*}{ New York } & New York City & Public & October 3, 2011 \\
\hline & New York City & Contract & October 3, 2011 \\
\hline & Buffalo & Public & June 11, 2013 \\
\hline & Buffalo & Contract & June 11, 2013 \\
\hline & Buffalo & Private & June 11, 2013 \\
\hline & Rochester & Public & May 20, 2014 \\
\hline & Rochester & Contract & May 20, 2014 \\
\hline & Rochester & Private & May 20, 2014 \\
\hline & Woodstock & Public & November 18, 2014 \\
\hline & Yonkers & Public & November 1, 2014 \\
\hline \multirow[t]{6}{*}{ North Carolina } & Carrboro & Public & October 16, 2012 \\
\hline & Charlotte & Public & February 28, 2014 \\
\hline & Cumberland County & Public & September 6, 2011 \\
\hline & Durham & Public & February 1, 2011 \\
\hline & Durham County & Public & October 1, 2012 \\
\hline & Spring Lake & Public & June 25, 2012 \\
\hline \multirow[t]{13}{*}{ Ohio } & Alliance & Public & December 1, 2014 \\
\hline & Akron & Public & October 29, 2013 \\
\hline & Cincinnati & Public & August 1, 2010 \\
\hline & Cleveland & Public & September 26, 2011 \\
\hline & Canton & Public & May 15, 2013 \\
\hline & Cuyahoga County & Public & September 30, 2012 \\
\hline & Franklin County & Public & June 19, 2012 \\
\hline & Hamilton County & Public & March 1, 2012 \\
\hline & Lucas County & Public & October 29, 2013 \\
\hline & Massillon & Public & January 3, 2014 \\
\hline & Stark County & Public & May 1, 2013 \\
\hline & Summit County & Public & September 1, 2012 \\
\hline & Youngstown & Public & March 19, 2014 \\
\hline \multirow[t]{2}{*}{ Oregon } & Multnomah County & Public & October 10, 2007 \\
\hline & Portland & Public & July 9, 2014 \\
\hline \multirow[t]{3}{*}{ Pennsylvania } & Allegheny County & Public & November 24, 2014 \\
\hline & Lancaster & Public & October 1, 2014 \\
\hline & Philadelphia & Public & June 29, 2011 \\
\hline
\end{tabular}


Table 3: (continued)

\begin{tabular}{|c|c|c|c|}
\hline State & Jurisdiction & Law Type & Start Date \\
\hline & Philadelphia & Contract & June 29,2011 \\
\hline & Philadelphia & Private & June 29, 2011 \\
\hline & Pittsburgh & Public & December 17, 2012 \\
\hline \multirow[t]{4}{*}{ Rhode Island } & State & Public & July 15, 2013 \\
\hline & State & Contract & July 15, 2013 \\
\hline & State & Private & July 15, 2013 \\
\hline & Providence & Public & April 1, 2009 \\
\hline \multirow[t]{2}{*}{ Tennessee } & Memphis & Public & July 9, 2010 \\
\hline & Hamilton County & Public & January 1, 2012 \\
\hline \multirow[t]{2}{*}{ Texas } & Austin & Public & October 16, 2008 \\
\hline & Travis County & Public & April 15, 2008 \\
\hline \multirow[t]{11}{*}{ Virginia } & Newport News & Public & October 1, 2012 \\
\hline & Richmond & Public & March 25, 2013 \\
\hline & Portsmouth & Public & April 1, 2013 \\
\hline & Norfolk & Public & July 23, 2013 \\
\hline & Petersburg & Public & September 3, 2013 \\
\hline & Alexandria & Public & March 19, 2014 \\
\hline & Arlington County & Public & November 3, 2014 \\
\hline & Charlottesville & Public & March 1, 2014 \\
\hline & Danville & Public & June 3, 2014 \\
\hline & Fredericksburg & Public & January 1, 2014 \\
\hline & Virginia Beach & Public & November 1, 2013 \\
\hline \multirow[t]{4}{*}{ Washington } & Seattle & Public & April 24, 2009 \\
\hline & Seattle & Contract & January 1, 2013 \\
\hline & Spokane & Public & July 31, 2014 \\
\hline & Pierce County & Public & January 1, 2012 \\
\hline \multirow[t]{2}{*}{ Wisconsin } & Dane County & Public & February 1, 2014 \\
\hline & Milwaukee & Public & October 7, 2011 \\
\hline
\end{tabular}




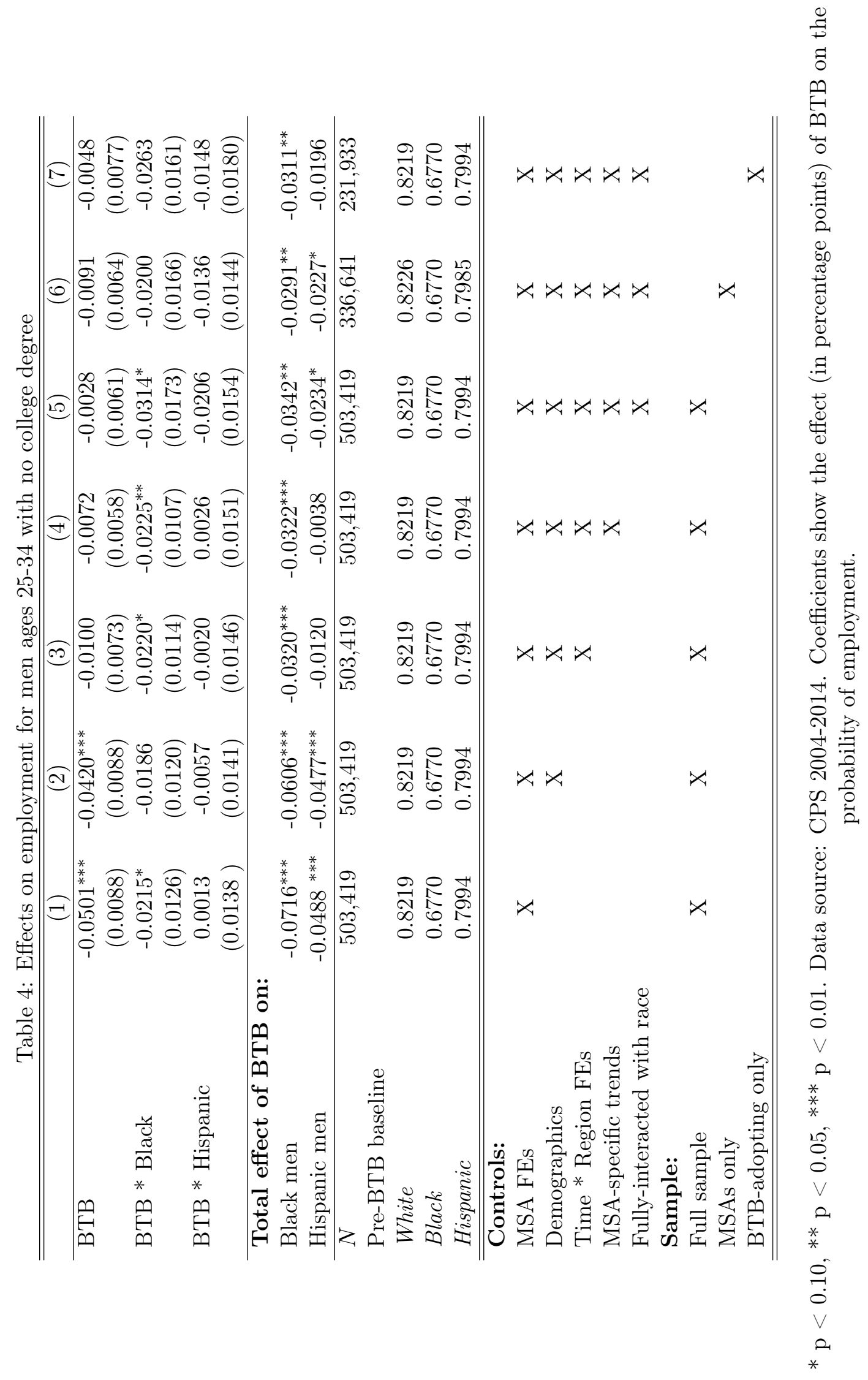


Table 5: Effects on Employment for Men ages 25-34 with no college degree

\begin{tabular}{|c|c|c|c|}
\hline & White & Black & Hispanic \\
\hline \multicolumn{4}{|l|}{ Northeast } \\
\hline \multirow[t]{2}{*}{ BTB } & -0.0163 & $-0.0476^{* *}$ & -0.0266 \\
\hline & $(0.0096)$ & $(0.0185)$ & $(0.0170)$ \\
\hline$N$ & 70,298 & 7,355 & 9,673 \\
\hline Pre-BTB baseline & 0.8193 & 0.6447 & 0.7605 \\
\hline \multicolumn{4}{|l|}{ Midwest } \\
\hline \multirow{2}{*}{ ВTB } & 0.0140 & $-0.0492^{* *}$ & -0.0464 \\
\hline & $(0.0081)$ & $(0.0195)$ & $(0.0271)$ \\
\hline$N$ & 107,215 & 11,364 & 7,485 \\
\hline Pre-BTB baseline & 0.8192 & 0.6390 & 0.8170 \\
\hline \multicolumn{4}{|l|}{ South } \\
\hline \multirow[t]{2}{*}{ BTB } & 0.0098 & -0.0164 & -0.0302 \\
\hline & $(0.0144)$ & $(0.0302)$ & $(0.0368)$ \\
\hline$N$ & 108,565 & 35,423 & 20,974 \\
\hline Pre-BTB baseline & 0.8328 & 0.7094 & 0.8357 \\
\hline \multicolumn{4}{|l|}{ West } \\
\hline \multirow[t]{2}{*}{ ВTB } & -0.0184 & $-0.0598^{* *}$ & -0.0086 \\
\hline & $(0.0104)$ & $(0.0245)$ & $(0.0243)$ \\
\hline$N$ & 87,159 & 5,730 & 32,178 \\
\hline Pre-BTB baseline & 0.8171 & 0.6780 & 0.7978 \\
\hline \multicolumn{4}{|l|}{ Controls: } \\
\hline MSA FEs & $\mathrm{X}$ & $\mathrm{X}$ & $\mathrm{X}$ \\
\hline Demographics & $\mathrm{X}$ & $\mathrm{X}$ & $\mathrm{X}$ \\
\hline Time FEs & $\mathrm{X}$ & $\mathrm{X}$ & $\mathrm{X}$ \\
\hline MSA-specific trends & $\mathrm{X}$ & $\mathrm{X}$ & $\mathrm{X}$ \\
\hline
\end{tabular}

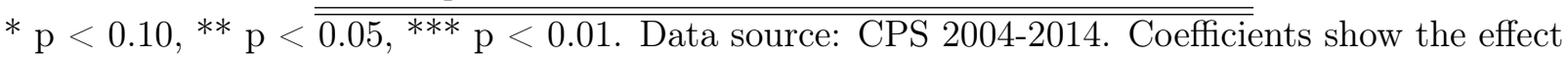
(in percentage points) of BTB on the probability of employment. 
Table 6: Effects on Employment for Men ages 25-34 with no college degree

\begin{tabular}{lcccccc}
\hline \hline & \multicolumn{2}{c}{ White } & \multicolumn{2}{c}{ Black } & \multicolumn{2}{c}{ Hispanic } \\
& $(1)$ & $(2)$ & $(3)$ & $(4)$ & $(5)$ & $(6)$ \\
\hline BTB & 0.0213 & 0.0456 & -0.0170 & 0.1194 & 0.0054 & $0.3147^{*}$ \\
& $(0.0226)$ & $(0.0896)$ & $(0.0540)$ & $(0.2927)$ & $(0.0355)$ & $(0.1873)$ \\
BTB * Unemp. Rate & -0.0031 & -0.0100 & -0.0022 & -0.0407 & -0.0036 & -0.0934 \\
& $(0.0030)$ & $(0.0268)$ & $(0.0064)$ & $(0.0831)$ & $(0.0043)$ & $(0.0562)$ \\
& & 0.0005 & & 0.0026 & & 0.0061 \\
BTB * (Unemp. Rate) ${ }^{2}$ & & $(0.0019)$ & & $(0.0056)$ & & $(0.0039)$ \\
\hline Total effect of BTB: & & & & & & \\
$5 \%$ Unemployment & 0.0058 & 0.0081 & -0.0280 & -0.0191 & -0.0126 & 0.0002 \\
$6 \%$ Unemployment & 0.0027 & 0.0036 & -0.0302 & -0.0312 & -0.0162 & -0.0261 \\
$7 \%$ Unemployment & -0.0004 & 0.0001 & $-0.0324^{*}$ & -0.0381 & -0.0198 & $-0.0402^{*}$ \\
$8 \%$ Unemployment & -0.0035 & -0.0024 & $-0.0346^{* *}$ & $-0.0398^{*}$ & $-0.0234^{*}$ & $-0.0421^{* *}$ \\
$9 \%$ Unemployment & -0.0066 & -0.0039 & $-0.0368^{* *}$ & $-0.0363^{* *}$ & $-0.0270^{*}$ & $-0.0318^{* *}$ \\
\hline$N$ & 373,237 & 373,237 & 59,872 & 59,872 & 70,310 & 70,310 \\
Pre-BTB baseline & 0.8219 & 0.8219 & 0.6770 & 0.6770 & 0.7994 & 0.7994 \\
\hline \hline Controls: & & & & & & \\
MSA FEs & $\mathrm{X}$ & $\mathrm{X}$ & $\mathrm{X}$ & $\mathrm{X}$ & $\mathrm{X}$ & $\mathrm{X}$ \\
Demographics & $\mathrm{X}$ & $\mathrm{X}$ & $\mathrm{X}$ & $\mathrm{X}$ & $\mathrm{X}$ & $\mathrm{X}$ \\
Time * Region FEs & $\mathrm{X}$ & $\mathrm{X}$ & $\mathrm{X}$ & $\mathrm{X}$ & $\mathrm{X}$ & $\mathrm{X}$ \\
MSA-specific trends & $\mathrm{X}$ & $\mathrm{X}$ & $\mathrm{X}$ & $\mathrm{X}$ & $\mathrm{X}$ & $\mathrm{X}$ \\
\hline \hline
\end{tabular}

$* \overline{\overline{\mathrm{p}<0.10,}{ }^{* *} \mathrm{p}<0.05,{ }^{* * *} \mathrm{p}<0.01 \text {. Data source: CPS 2004-2014. Coefficients show the effect }}$ (in percentage points) of BTB on the probability of employment. 


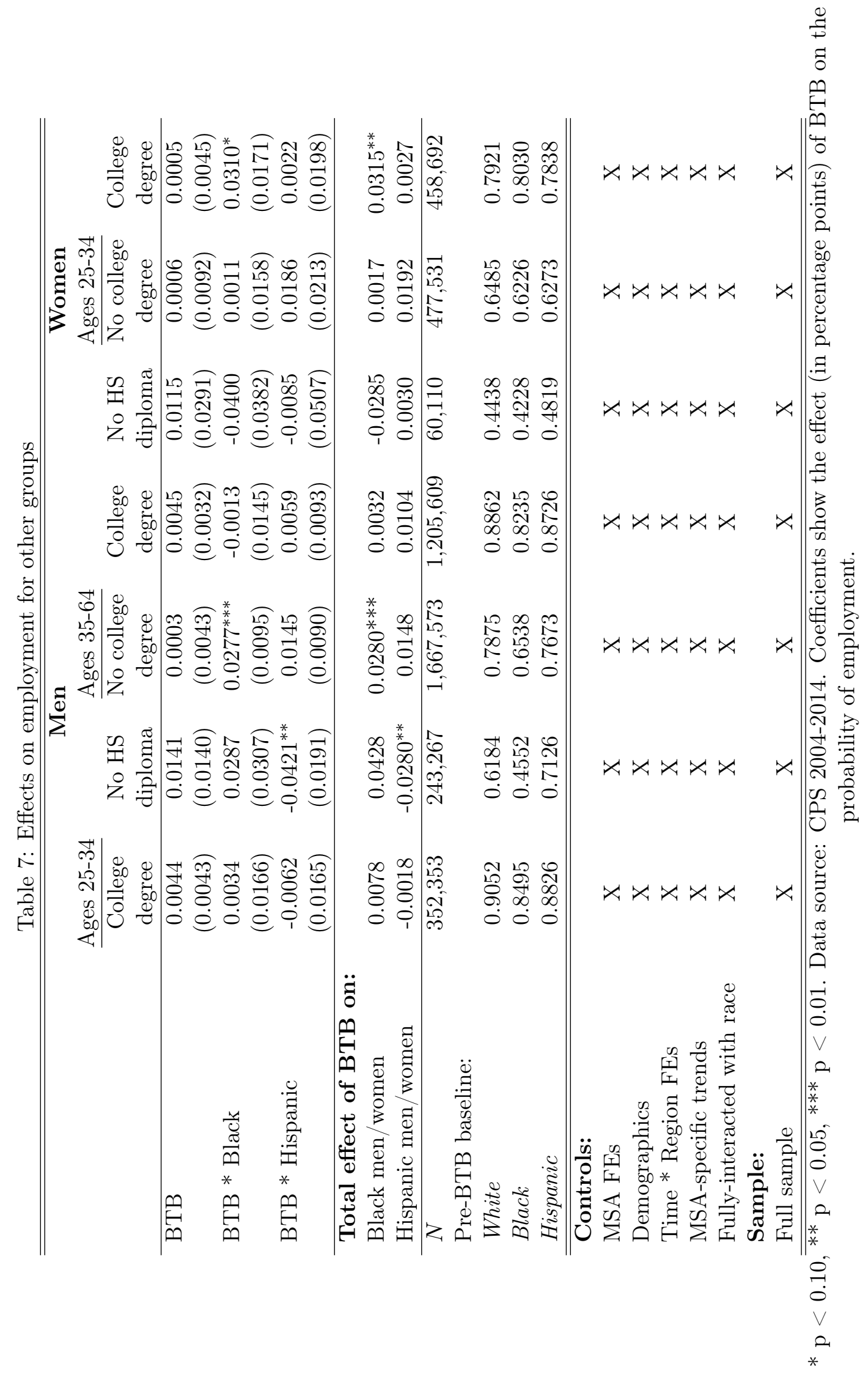


Table 8: Effects on Employment for Men ages 25-34 with no college degree

\begin{tabular}{lccc}
\hline \hline & White & Black & Hispanic \\
\hline BTB -0 to 1 year & -0.0079 & -0.0265 & -0.0161 \\
& $(0.0063)$ & $(0.0167)$ & $(0.0144)$ \\
BTB -1 to 2 years & 0.0006 & $-0.0514^{* * *}$ & $-0.0301^{*}$ \\
& $(0.0088)$ & $(0.0182)$ & $(0.0154)$ \\
BTB -2 to 3 years & 0.0089 & $-0.0406^{*}$ & -0.0257 \\
& $(0.0121)$ & $(0.0216)$ & $(0.0176)$ \\
BTB -3 to 4 years & 0.0083 & $-0.0839^{* * *}$ & -0.0017 \\
& $(0.0150)$ & $(0.0261)$ & $(0.0315)$ \\
BTB $-4+$ years & -0.0004 & $-0.0772^{* *}$ & -0.0039 \\
& $(0.0157)$ & $(0.0328)$ & $(0.0352)$ \\
\hline$N$ & 373,237 & 59,872 & 70,310 \\
Pre-BTB baseline & 0.8219 & 0.6770 & 0.7994 \\
\hline \hline
\end{tabular}

Controls:

MSA FEs

Demographics

Time FEs $\quad \mathrm{X} \quad \mathrm{X} \quad \mathrm{X}$

$\mathrm{X} \quad \mathrm{X} \quad \mathrm{X}$

MSA-specific trends $\mathrm{X} \quad \mathrm{X} \quad \mathrm{X}$

${ }^{*} \mathrm{p}<0.10,{ }^{*} \mathrm{p}<\overline{\overline{0.05,{ }^{* * *} \mathrm{p}<0.01 . \text { Data source: CPS 2004-2014. Coefficients show the effect }}}$ (in percentage points) of BTB on the probability of employment. 


\section{A Appendix Figures and Tables}

Figure A-1: Jurisdictions with BTB policies, 2004 to 2014
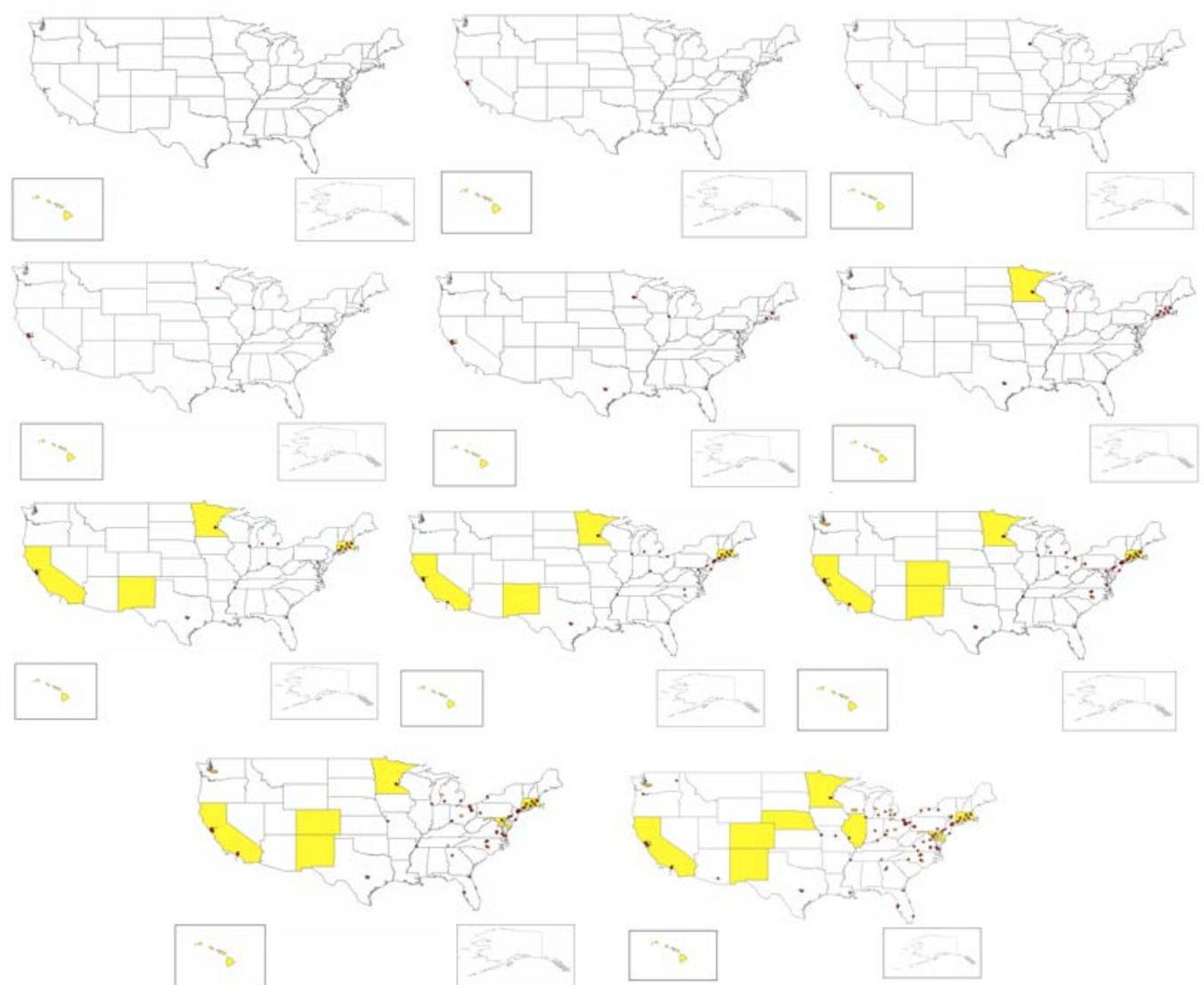

Maps are by year, beginning with 2004 in the top left corner, 2005 at the top center, 2006 at the top right, and continuing sequentially by row. Jurisdictions with BTB policies are represented by yellow shading (state-level policies), orange shading (county-level policies), and red dots (city-level policies.) 
Table A-1: Effect of state characteristics on BTB adoption

\begin{tabular}{|c|c|c|c|c|c|c|c|}
\hline & $(1)$ & $(2)$ & $(3)$ & $(4)$ & $(5)$ & $(6)$ & \\
\hline Percent Urban & $\begin{array}{c}0.0146^{* * *} \\
(0.0039)\end{array}$ & & & & & & $\begin{array}{c}0.0062 \\
(0.0067)\end{array}$ \\
\hline Percent Black & & $\begin{array}{c}0.0146^{* * *} \\
(00053)\end{array}$ & & & & & $\begin{array}{c}0.0175^{* *} \\
(0.0073)\end{array}$ \\
\hline Percent Hispanic & & & $\begin{array}{c}0.0083 \\
(0.0075)\end{array}$ & & & & $\begin{array}{c}0.0063 \\
(0.0098)\end{array}$ \\
\hline Percent Poverty & & & & $\begin{array}{c}-0.0116 \\
(0.0202)\end{array}$ & & & $\begin{array}{c}-0.0296 \\
(0.0301)\end{array}$ \\
\hline Percent Bachelor's Degree or More & & & & & $\begin{array}{c}0.0327^{* *} \\
(0.0133)\end{array}$ & & $\begin{array}{l}-0.0073 \\
(0.0168)\end{array}$ \\
\hline Median FT Earnings (Male) & & & & & & $\begin{array}{c}0.0001^{* * *} \\
(0.0000)\end{array}$ & $\begin{array}{c}0.0000 \\
(0.0000)\end{array}$ \\
\hline
\end{tabular}

Notes: Outcome variable is whether any MSA in that state adopted BTB by December 2014.

Table A-2: Effect of state characteristics on date of first BTB policy in the state

\begin{tabular}{|c|c|c|c|c|c|c|c|}
\hline & $(1)$ & $(2)$ & $(3)$ & $(4)$ & $(5)$ & $(6)$ & \\
\hline Percent Urban & $\begin{array}{c}-38.278^{* *} \\
(15.694)\end{array}$ & & & & & & $\begin{array}{c}-28.994 \\
(26.417)\end{array}$ \\
\hline Percent Black & & $\begin{array}{l}33.686^{* *} \\
(15.702)\end{array}$ & & & & & $\begin{array}{c}36.493 \\
(26.313)\end{array}$ \\
\hline Percent Hispanic & & & $\begin{array}{l}-24.210 \\
(21.671)\end{array}$ & & & & $\begin{array}{c}5.5919 \\
(31.106)\end{array}$ \\
\hline Percent Poverty & & & & $\begin{array}{l}98.132^{*} \\
(56.339)\end{array}$ & & & $\begin{array}{l}-23.346 \\
(107.03)\end{array}$ \\
\hline Percent Bachelor's Degree or More & & & & & $\begin{array}{l}-65.698 \\
(41.242)\end{array}$ & & $\begin{array}{l}-0.3367 \\
(65.684)\end{array}$ \\
\hline Median FT Earnings (Male) & & & & & & $\begin{array}{c}-0.1076^{* *} \\
(0.0471)\end{array}$ & $\begin{array}{c}-0.0535 \\
(0.0816)\end{array}$ \\
\hline
\end{tabular}

Notes: Outcome variable is the date of the first BTB policy adopted within the state, conditional on adopting at least one such policy by December 2014 . 


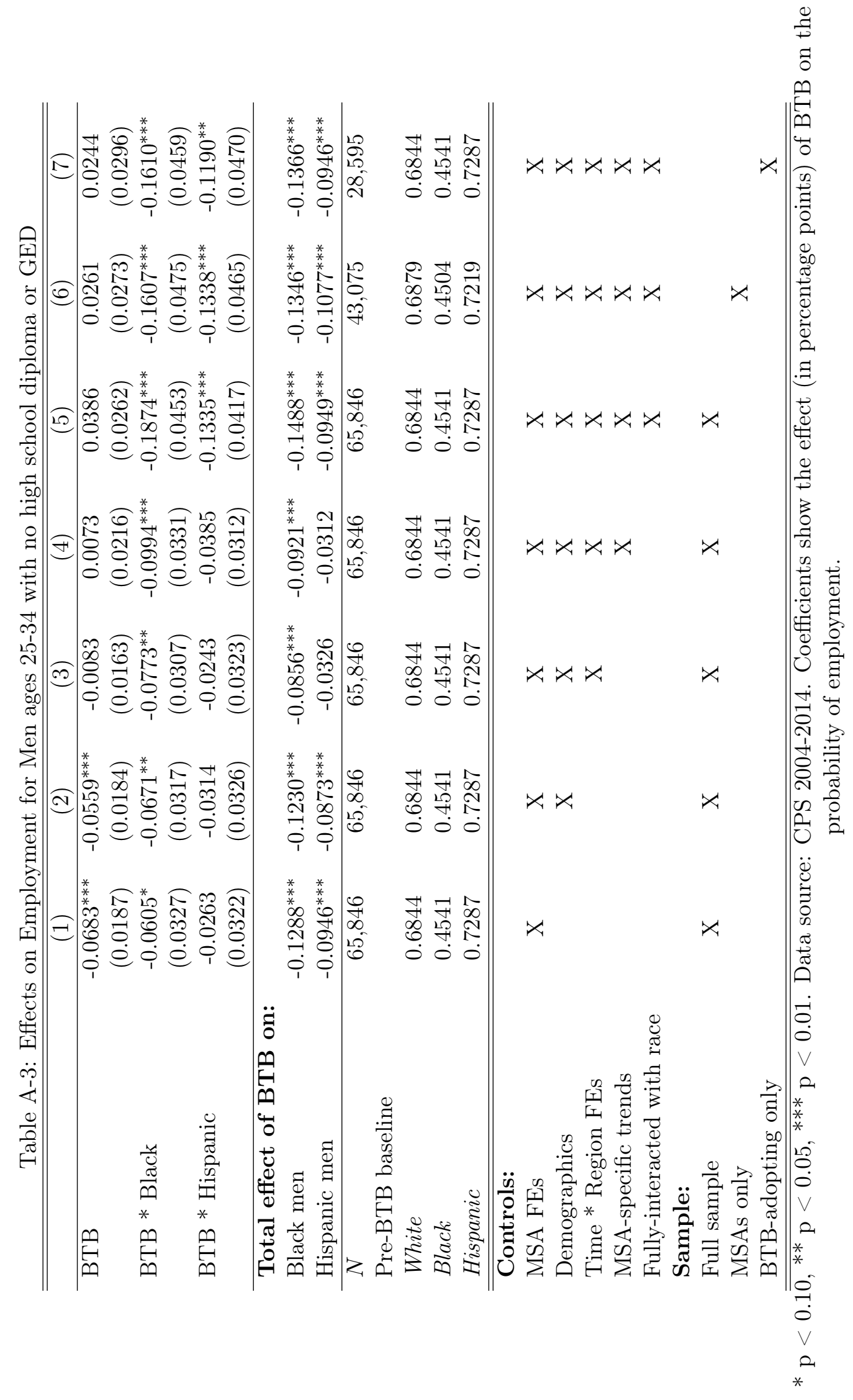


Table A-4: Effects on employment for men ages 25-34 with no college degree (Dropping AL-NE)

\begin{tabular}{|c|c|c|c|c|c|c|c|}
\hline & Drop AL & Drop AK & Drop AZ & Drop AR & Drop CA & Drop CO & Drop CT \\
\hline \multirow[t]{2}{*}{ BTB } & -0.0025 & -0.0026 & -0.0028 & -0.0025 & -0.0016 & -0.0014 & -0.0030 \\
\hline & $(0.0061)$ & $(0.0061)$ & $(0.0061)$ & $(0.0061)$ & $(0.0067)$ & $(0.0064)$ & $(0.0063)$ \\
\hline \multirow[t]{2}{*}{ BTB * Black } & $-0.0314^{*}$ & $-0.0307^{*}$ & $-0.0320^{*}$ & $-0.0325^{*}$ & -0.0290 & $-0.0309^{*}$ & $-0.0306^{*}$ \\
\hline & $(0.0174)$ & $(0.0173)$ & $(0.0174)$ & $(0.0174)$ & $(0.0184)$ & $(0.0179)$ & $(0.0179)$ \\
\hline \multirow[t]{2}{*}{ BTB $*$ Hispanic } & -0.0209 & -0.0207 & -0.0211 & -0.0210 & -0.0222 & $-0.0330^{* *}$ & -0.0183 \\
\hline & $(0.0154)$ & $(0.0156)$ & $(0.0158)$ & $(0.0154)$ & $(0.0150)$ & $(0.0142)$ & $(0.0164)$ \\
\hline \multicolumn{8}{|c|}{ Total effect of BTB on: } \\
\hline Black men & $-0.0339^{* *}$ & $-0.0333^{* *}$ & $-0.0348^{* *}$ & $-0.0350^{* *}$ & $-0.0306^{*}$ & $-0.0323^{* *}$ & $-0.0336^{* *}$ \\
\hline Hispanic men & $-0.0234^{*}$ & $-0.0233^{*}$ & $-0.0239^{*}$ & $-0.0235^{*}$ & $-0.0238^{*}$ & $-0.0344^{* * *}$ & -0.0213 \\
\hline \multirow[t]{2}{*}{$N$} & 496,481 & 496,711 & 496,576 & 495,676 & 467,052 & 492,347 & 495,400 \\
\hline & Drop DE & Drop DC & Drop FL & Drop GA & Drop HI & Drop ID & Drop IL \\
\hline \multirow[t]{2}{*}{ BTB } & -0.0030 & -0.0033 & -0.0034 & -0.0032 & -0.0027 & -0.0029 & -0.0040 \\
\hline & $(0.0063)$ & $(0.0061)$ & $(0.0062)$ & $(0.0063)$ & $(0.0061)$ & $(0.0061)$ & $(0.0063)$ \\
\hline \multirow[t]{2}{*}{ BTB * Black } & $-0.0336^{*}$ & -0.0246 & $-0.0352^{* *}$ & $-0.0296^{*}$ & $-0.0316^{*}$ & $-0.0311^{*}$ & -0.0284 \\
\hline & $(0.0177)$ & $(0.0157)$ & $(0.0172)$ & $(0.0177)$ & $(0.0173)$ & $(0.0174)$ & $(0.1094)$ \\
\hline \multirow[t]{2}{*}{ BTB $*$ Hispanic } & -0.0226 & -0.0195 & -0.0195 & -0.0224 & -0.0225 & -0.0204 & -0.0204 \\
\hline & $(0.0158)$ & $(0.0154)$ & $(0.0156)$ & $(0.0158)$ & $(0.0161)$ & $(0.0154)$ & $(0.0166)$ \\
\hline \multicolumn{8}{|c|}{ Total effect of BTB on: } \\
\hline Black men & $-0.0366^{* *}$ & $-0.0279^{* *}$ & $-0.0386^{* *}$ & $-0.0328^{* *}$ & $-0.0343^{* *}$ & $-0.0340^{* *}$ & $-0.0324^{*}$ \\
\hline Hispanic men & $-0.0256^{*}$ & $-0.0228^{*}$ & $-0.0229^{*}$ & $-0.0256^{*}$ & $-0.0252^{*}$ & $-0.0233^{*}$ & $-0.0244^{*}$ \\
\hline \multirow[t]{2}{*}{$N$} & 495,456 & 499,741 & 485,197 & 492,170 & 501,213 & 496,261 & 488,433 \\
\hline & Drop IN & Drop IA & Drop KS & Drop KY & Drop LA & Drop ME & Drop MD \\
\hline \multirow[t]{2}{*}{ BTB } & -0.0022 & -0.0033 & -0.0027 & -0.0032 & -0.0028 & -0.0030 & -0.0030 \\
\hline & $(0.0061)$ & $(0.0061)$ & $(0.0062)$ & $(0.0061)$ & $(0.0061)$ & $(0.0061)$ & $(0.0063)$ \\
\hline \multirow[t]{2}{*}{ BTB * Black } & $-0.0308^{*}$ & $-0.0307^{*}$ & $-0.0329^{*}$ & $-0.0306^{*}$ & $-0.0322^{*}$ & $-0.0308^{*}$ & $-0.0354^{*}$ \\
\hline & $(0.0175)$ & $(0.0173)$ & $(0.0174)$ & $(0.0175)$ & $(0.0178)$ & $(0.0173)$ & $(0.0198)$ \\
\hline \multirow[t]{2}{*}{ BTB $*$ Hispanic } & -0.0205 & -0.0205 & -0.0192 & -0.0199 & -0.0196 & -0.0204 & -0.0212 \\
\hline & $(0.0154)$ & $(0.0155)$ & $(0.0154)$ & $(0.0154)$ & $(0.0153)$ & $(0.0154)$ & $(0.0158)$ \\
\hline \multicolumn{8}{|c|}{ Total effect of BTB on: } \\
\hline Black men & $-0.0330^{* *}$ & $-0.0340^{* *}$ & $-0.0356^{* *}$ & $-0.0338^{* *}$ & $-0.0350^{* *}$ & $-0.0338^{* *}$ & $-0.0384^{* *}$ \\
\hline Hispanic men & $-0.0227^{*}$ & $-0.0238^{*}$ & $-0.0219^{*}$ & $-0.0231^{*}$ & $-0.0224^{*}$ & $-0.0234^{*}$ & $-0.0242^{*}$ \\
\hline \multirow[t]{2}{*}{$N$} & 493,901 & 493,365 & 495,607 & 494,402 & 497,026 & 493,945 & 494,161 \\
\hline & Drop MA & Drop MI & Drop MN & Drop MS & Drop MO & Drop MT & Drop NE \\
\hline \multirow[t]{2}{*}{ BTB } & -0.0020 & -0.0051 & -0.0049 & -0.0036 & -0.0026 & -0.0030 & -0.0033 \\
\hline & $(0.0062)$ & $(0.0056)$ & $(0.0060)$ & $(0.0060)$ & $(0.0062)$ & $(0.0061)$ & $(0.0063)$ \\
\hline \multirow[t]{2}{*}{ BTB * Black } & $-0.0325^{*}$ & -0.0272 & -0.0277 & -0.0290 & $-0.0294^{*}$ & $-0.0309^{*}$ & $-0.0306^{*}$ \\
\hline & $(0.0174)$ & $(0.0177)$ & $(0.0179)$ & $(0.0174)$ & $(0.0172)$ & $(0.0173)$ & $(0.0174)$ \\
\hline \multirow[t]{2}{*}{ BTB * Hispanic } & -0.0218 & -0.0187 & -0.0179 & -0.0196 & -0.0205 & -0.0192 & -0.0194 \\
\hline & $(0.0161)$ & $(0.0156)$ & $(0.0154)$ & $(0.0154)$ & $(0.0155)$ & $(0.0151)$ & $(0.0157)$ \\
\hline \multicolumn{8}{|c|}{ Total effect of BTB on: } \\
\hline Black men & $-0.0345^{* *}$ & $-0.0323^{* *}$ & $-0.0326^{* *}$ & $-0.0326^{* *}$ & $-0.0320^{* *}$ & $-0.0339^{* *}$ & $-0.0339^{* *}$ \\
\hline Hispanic men & $-0.0238^{*}$ & $-0.0238^{*}$ & $-0.0228^{*}$ & $-0.0232^{*}$ & $-0.0231^{*}$ & $-0.0222^{*}$ & $-0.0227^{*}$ \\
\hline$N$ & 497,858 & 490,480 & 492,456 & 497,803 & 492,912 & 497,540 & 495,664 \\
\hline
\end{tabular}


Table A-5: Effects on employment for men ages 25-34 with no college degree (Dropping NV-WY)

\begin{tabular}{|c|c|c|c|c|c|c|c|}
\hline & Drop NV & Drop NH & Drop NJ & Drop NM & Drop NY & Drop NC & Drop ND \\
\hline \multirow[t]{2}{*}{ BTB } & -0.0028 & -0.0041 & 0.0009 & -0.0021 & -0.0013 & -0.0031 & -0.0030 \\
\hline & $(0.0061)$ & $(0.0061)$ & $(0.0059)$ & $(0.0061)$ & $(0.0062)$ & $(0.0061)$ & $(0.0062)$ \\
\hline \multirow[t]{2}{*}{ BTB * Black } & $-0.0307^{*}$ & $-0.0294^{*}$ & $-0.0350^{*}$ & $-0.0322^{*}$ & $-0.0337^{*}$ & $-0.0315^{*}$ & $-0.0312^{*}$ \\
\hline & $(0.0175)$ & $(0.0173)$ & $(0.0195)$ & $(0.0174)$ & $(0.0191)$ & $(0.0179)$ & $(0.0174)$ \\
\hline \multirow[t]{2}{*}{ BTB $*$ Hispanic } & -0.0196 & -0.0201 & $-0.0348^{*}$ & -0.0200 & -0.0268 & -0.0192 & -0.0204 \\
\hline & $(0.0162)$ & $(0.0155)$ & $(0.0177)$ & $(0.0156)$ & $(0.0167)$ & $(0.0153)$ & $(0.0154)$ \\
\hline \multicolumn{8}{|c|}{ Total effect of BTB on: } \\
\hline Black men & $-0.0335^{* *}$ & $-0.0335^{* *}$ & $-0.0341^{* *}$ & $-0.0343^{* *}$ & $-0.0350^{* *}$ & $-0.0346^{* *}$ & $-0.0342^{* *}$ \\
\hline Hispanic men & -0.0224 & $-0.0242^{*}$ & $-0.0339^{* *}$ & $-0.0221^{*}$ & $-0.0281^{*}$ & $-0.0223^{*}$ & $-0.0234^{*}$ \\
\hline \multirow[t]{2}{*}{$N$} & 494,556 & 493,914 & 496,140 & 498,281 & 486,414 & 493,827 & 496,685 \\
\hline & Drop $\mathrm{OH}$ & Drop OK & Drop OR & Drop PA & Drop RI & Drop SC & Drop SD \\
\hline \multirow[t]{2}{*}{ BTB } & -0.0024 & -0.0029 & -0.0009 & -0.0007 & -0.0031 & -0.0033 & -0.0028 \\
\hline & $(0.0065)$ & $(0.0061)$ & $(0.0060)$ & $(0.0061)$ & $(0.0064)$ & $(0.0061)$ & $(0.0061)$ \\
\hline \multirow[t]{2}{*}{ BTB * Black } & $-0.0335^{*}$ & $-0.0312^{*}$ & $-0.0337^{*}$ & $-0.0318^{*}$ & $-0.0343^{* *}$ & -0.0257 & $-0.0311^{*}$ \\
\hline & $(0.0179)$ & $(0.0173)$ & $(0.0174)$ & $(0.0181)$ & $(0.0176)$ & $(0.0163)$ & $(0.0173)$ \\
\hline \multirow[t]{2}{*}{ BTB * Hispanic } & -0.0188 & -0.0204 & -0.0236 & $-0.0276^{*}$ & -0.0177 & -0.0203 & -0.0209 \\
\hline & $(0.0155)$ & $(0.0154)$ & $(0.0156)$ & $(0.0151)$ & $(0.0153)$ & $(0.0154)$ & $(0.0155)$ \\
\hline \multicolumn{8}{|c|}{ Total effect of BTB on: } \\
\hline Black men & $-0.0359^{* *}$ & $-0.0341^{* *}$ & $-0.0346^{* *}$ & $-0.0325^{* *}$ & $-0.0374^{* *}$ & $-0.0290^{* *}$ & $-0.0339^{* *}$ \\
\hline Hispanic men & -0.0212 & $-0.0233^{*}$ & $-0.0245^{*}$ & $-0.0283^{* *}$ & -0.0208 & $-0.0236^{*}$ & $-0.0237^{*}$ \\
\hline \multirow[t]{2}{*}{$N$} & 486,450 & 496,983 & 495,592 & 487,592 & 496,056 & 496,134 & 495,479 \\
\hline & Drop TN & Drop TX & Drop UT & Drop VT & Drop VA & Drop WA & Drop WV \\
\hline \multirow[t]{2}{*}{ BTB } & -0.0028 & -0.0020 & -0.0025 & -0.0027 & -0.0009 & -0.0039 & -0.0033 \\
\hline & $(0.0061)$ & $(0.0061)$ & $(0.0061)$ & $(0.0062)$ & $(0.0060)$ & $(0.0062)$ & $(0.0061)$ \\
\hline \multirow[t]{2}{*}{ BTB * Black } & $-0.0325^{*}$ & $-0.0347^{*}$ & $-0.0315^{*}$ & $-0.0314^{*}$ & $-0.0417^{* * *}$ & $-0.0311^{*}$ & $-0.0313^{*}$ \\
\hline & $(0.0176)$ & $(0.0173)$ & $(0.0174)$ & $(0.0173)$ & $(0.0148)$ & $(0.0175)$ & $(0.0173)$ \\
\hline \multirow[t]{2}{*}{ BTB $*$ Hispanic } & -0.0206 & -0.0195 & -0.0203 & -0.0206 & -0.0212 & -0.0206 & -0.0201 \\
\hline & $(0.0154)$ & $(0.0155)$ & $(0.0155)$ & $(0.0156)$ & $(0.0156)$ & $(0.0160)$ & $(0.0154)$ \\
\hline \multicolumn{8}{|c|}{ Total effect of BTB on: } \\
\hline Black men & $-0.0353^{* *}$ & $-0.0367^{* *}$ & $-0.0340^{* *}$ & $-0.0341^{* *}$ & $-0.0426^{* * *}$ & $-0.0350^{* *}$ & $-0.0346^{* *}$ \\
\hline Hispanic men & $-0.0234^{*}$ & -0.0215 & $-0.0228^{*}$ & $-0.0233^{*}$ & $-0.0221^{*}$ & $-0.0245^{*}$ & $-0.0234^{*}$ \\
\hline \multirow[t]{2}{*}{$N$} & 495,074 & 473,775 & 494,033 & 496,126 & 493,967 & 494,843 & 495,288 \\
\hline & Drop WI & Drop WY & & & & & \\
\hline \multirow[t]{2}{*}{ BTB } & -0.0027 & -0.0026 & & & & & \\
\hline & $(0.0063)$ & $(0.0062)$ & & & & & \\
\hline \multirow[t]{2}{*}{ BTB * Black } & $-0.0329^{*}$ & $-0.0319^{*}$ & & & & & \\
\hline & $(0.0175)$ & $(0.0174)$ & & & & & \\
\hline \multirow[t]{2}{*}{ BTB $*$ Hispanic } & -0.0187 & -0.0185 & & & & & \\
\hline & $(0.0153)$ & $(0.0155)$ & & & & & \\
\hline \multicolumn{8}{|c|}{ Total effect of BTB on: } \\
\hline Black men & $-0.0356^{* *}$ & $-0.0345^{* *}$ & & & & & \\
\hline Hispanic men & -0.0214 & -0.0211 & & & & & \\
\hline$N$ & 493,532 & 494,375 & & & & & \\
\hline
\end{tabular}

